\title{
A fragment of secreted Hsp90 $\alpha$ carries properties that enable it to accelerate effectively both acute and diabetic wound healing in mice
}

\author{
Chieh-Fang Cheng, ${ }^{1}$ Divya Sahu, ${ }^{1}$ Fred Tsen, ${ }^{1}$ Zhengwei Zhao, ${ }^{2}$ Jianhua Fan, ${ }^{1}$ Rosie Kim, ${ }^{1}$ \\ Xinyi Wang, ${ }^{1}$ Kathryn O'Brien, ${ }^{1}$ Yong Li, ${ }^{3}$ Yuting Kuang,, ${ }^{1}$ Mei Chen, ${ }^{1}$ David T. Woodley, ${ }^{1}$ and Wei Li' \\ 1Department of Dermatology and Norris Comprehensive Cancer Center, University of Southern California Keck School of Medicine, \\ Los Angeles, California, USA. ${ }^{2}$ State Key Laboratory of Cancer Biology, Department of Gastrointestinal Surgery, and \\ ${ }^{3}$ Department of Plastic Surgery, Xijing Hospital, Fourth Military Medical University, Xian, China.
}

\begin{abstract}
Wounds that fail to heal in a timely manner, for example, diabetic foot ulcers, pose a health, economic, and social problem worldwide. For decades, conventional wisdom has pointed to growth factors as the main driving force of wound healing; thus, growth factors have become the center of therapeutic developments. To date, becaplermin (recombinant human PDGF-BB) is the only US FDA-approved growth factor therapy, and it shows modest efficacy, is costly, and has the potential to cause cancer in patients. Other molecules that drive wound healing have therefore been sought. In this context, it has been noticed that wounds do not heal without the participation of secreted Hsp90 $\alpha$. Here, we report that a 115-aa fragment of secreted Hsp90 $\alpha$ (F-5) acts as an unconventional wound healing agent in mice. Topical application of F-5 peptide promoted acute and diabetic wound closure in mice far more effectively than did PDGF-BB. The stronger effect of F-5 was due to 3 properties not held by conventional growth factors: its ability to recruit both epidermal and dermal cells; the fact that its ability to promote dermal cell migration was not inhibited by TGF- $\beta$; and its ability to override the inhibitory effects of hyperglycemia on cell migration in diabetes. The discovery of F-5 challenges the long-standing paradigm of wound healing factors and reveals a potentially more effective and safer agent for healing acute and diabetic wounds.
\end{abstract}

\section{Introduction}

According to the Wound Healing Society, about $15 \%$ of older adults in the US suffer from chronic wounds, including predominantly venous stasis ulcers, pressure ulcers (bedsores), and diabetic (neuropathic) foot ulcers $(1,2)$. Every year 2 to 3 million more Americans are diagnosed with various types of chronic wounds. For instance, an estimated $18 \%$ of diabetic patients over the age of 65 in the US have nonhealing foot ulcers (3). In this particular patient population, the number of wound infection-caused leg amputations is approaching 100,000 per year. Worldwide, it is estimated that a lower limb is lost every 30 seconds as result of diabetic wound infection (2). The surgical procedure, hospitalization, and aftermath of wound care can cost US taxpayers $\$ 100,000$ per patient (in a 24-month period) and, not to mention, compromise quality of the patients' lives. The collective health care cost of the various chronic wounds exceeds $\$ 25$ billion annually, a rapid increase due to increasing health care cost, an aging population, and a rise in the incidence of diabetes and obesity in the US. On top of the above, the continued lack of effective treatments of chronic wounds has further contributed to the scope of this devastating problem.

Since the discovery of the first growth factor in the late 1970s, it has become conventional wisdom that locally released growth factors in an injured tissue constitute the main driving force to heal the

Authorship note: Chieh-Fang Cheng, Divya Sahu, Fred Tsen, and Zhengwei Zhao contributed equally to this work.

Conflict of interest: The authors have declared that no conflict of interest exists. Citation for this article: J Clin Invest. 2011;121(11):4348-4361. doi:10.1172/JCI46475. wound $(4,5)$. Specifically, under this assumption, growth factors are responsible for promoting the lateral migration of epidermal keratinocytes to close the wound, the inward migration of dermal fibroblasts to remodel the damaged tissue, and migration of microvascular endothelial cells to rebuild vascularized neodermis in the wounded space $(6,7)$. Since the first report of the EGF clinical trial on wound healing in 1989 (8), more than a dozen growth factor trials have been conducted. The list includes (a) EGF on partialthickness wounds of skin grafts (8), on traumatic corneal epithelial defects (9), on tympanic membrane with chronic perforation (10), and on advanced diabetic foot ulcers $(11,12)$; (b) bFGF on partialthickness burn wounds of children (13), on second-degree burns (14), and on diabetic ulcers (15); (c) acidic FGF on partial-thickness burns and skin graft donor sites (16); (d) GM-CSF plus bFGF on pressure ulcers (17); and (e) PDGF-BB on chronic pressure and diabetic ulcers (18-22). Despite the fact that most of these doubleblinded trials reported promising clinical efficacies in humans, only the human recombinant PDGF-BB has received US FDA approval for treatment of limb diabetic ulcers (Regranex, becaplermin gel $0.01 \%$, Ortho-McNeil Pharmaceutical) (20). After its approval in 1997, multicenter, randomized, parallel trials showed that becaplermin, at $100 \mu \mathrm{g} / \mathrm{g}$ of PDGF-BB, improved, at best, $15 \%$ of complete wound closures (50\% treated versus 36\% placebo) (19-22). These results are not considered to be a cost-effective benefit for clinical practice $(23,24)$. In 2008 , the US FDA added a black box warning regarding increased risks for cancer mortality in patients who need extensive treatments ( $\geq 3$ tubes) of becaplermin gel. This significant side effect may not be surprising to cancer researchers, 
A
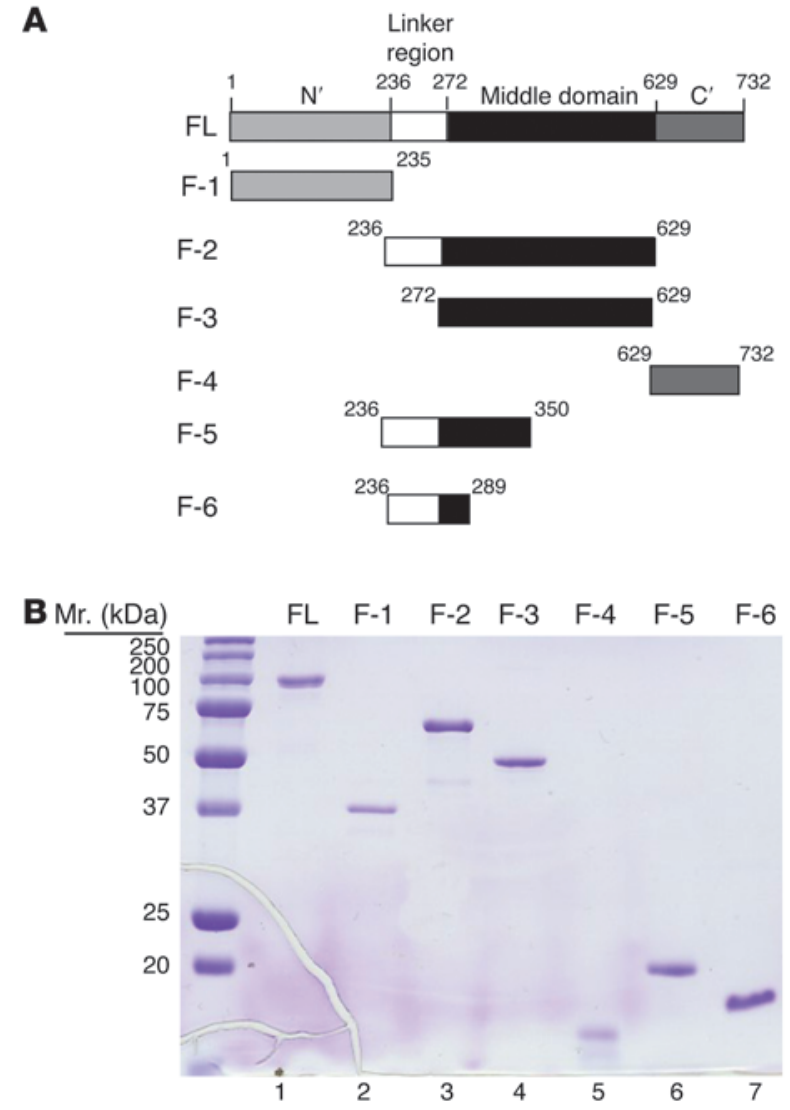

C

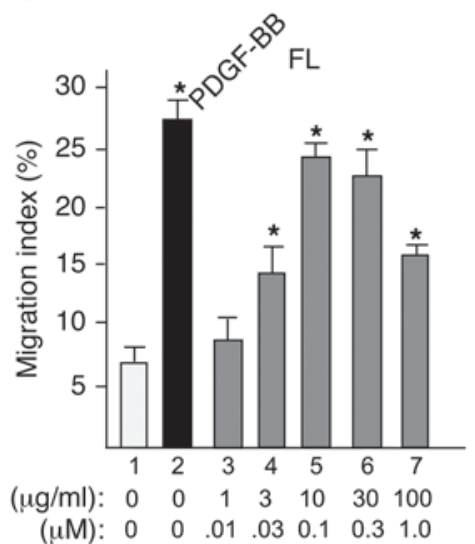

E

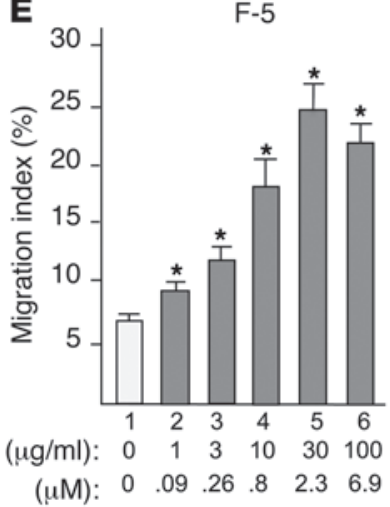

D

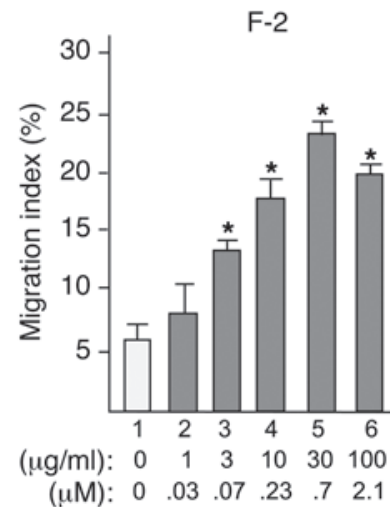

$\mathbf{F}$

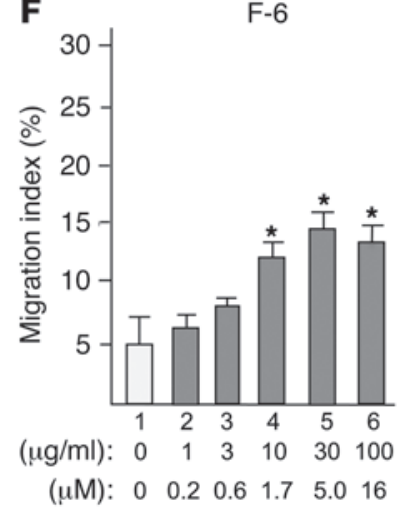

Figure 1

F-5 peptide retains the full promotility activity of full-length Hsp90 $\alpha$. (A) A schematic representation of 7 human Hsp90 $\alpha$ proteins/peptides (wild type and mutants). Each cDNA fragment by PCR was subcloned into pET15b and expressed in BL-21 bacteria, according to the manufacturer's protocol. Protein was sequentially purified by $\mathrm{Ni}^{+}$column and finally FPLC, prior to in vitro motility assays and in vivo wound healing assays. (B) A Coomassie Blue-stained SDS-PAGE gel to show the proteins after FPLC ( $3 \mu \mathrm{g} / \mathrm{lane})$. The first lane on far left is molecular weight markers. Mr, molecular weight. (C-F) Data of colloidal gold migration assay of serum-starved HDFs in response to PDGF-BB (15 ng/ml) and the full-length and the various fragments of $\mathrm{Hsp} 90 \alpha$, with the indicated concentrations, are presented. The negative results of F-1, F-3, and F-4 are not shown. Only the migration index (see ref. 38) of the migration experiments $\left(n=4,{ }^{*} P<0.05\right)$ is shown. Similar results were observed when in vitro wound healing scratch and the transwell assays were used. FL, full length.

since it was already known, years before the FDA approval of becaplermin gel, that overexpression of PDGF-BB (c-sis) or autocrine of its viral form, v-sis, will cause cell transformation (25), and yet the recommended dosage of PDGF-BB in becaplermin gel is more than 1,000 -fold higher than the range of the physiological PDGF-BB levels in human circulation (26).

So, what was against the conventional wisdom? Initially, in an entirely isolated study of ours, we noticed that FBS or its equivalent has been widely used in studies of human skin cells and wound healing. However, these human cells are never in contact with FBS in reality, instead they are bathed in human serum in the wound. We challenged the assumption that FBS and human serum share completely interchangeable factors for human skin cell migration. Results of our experiments showed that, while FBS equally stimulated migration of human epidermal and dermal cells, human serum only promoted human keratinocyte (HK) migration and halted human dermal fibroblast (HDF) and human microvascular endothelial cell (HDMEC) migration $(27,28)$. We further identified TGF- $\beta 3$ (not TGF- $\beta 1$ or TGF- $\beta 2$ ) in human serum that was responsible for the inhibitory effect of human serum on migration of the human dermal cells, which express 7- to 18-fold higher levels of the type II TGF- $\beta$ receptor (T $\beta$ RII) than human epidermal keratinocytes (28). In this case, however, TGF- $\beta 3$ is no troublemaker; instead it controls the "traffic" of the epidermal and dermal cell migration to ensure a speedy and proper closure of the wound (28). An important implication of these findings is that the conventional growth factors, such as PDGF-BB for dermal fibroblasts and VEGF-A for endothelial cells, may not be able to do the job, as they were hoped, in human wounds, because of the copresence of TGF- $\beta 3$.

We speculated that the source of the molecule driving the wound closure comes from secreted proteins by human skin cells at the wound edge in response to the injury. Protein purification allowed us to discover a novel wound healing-promoting factor, the secreted form of $\mathrm{Hsp} 90 \alpha$, from both $\mathrm{HDFs}$ and $\mathrm{HKs}(29,30)$. It is now clear that normal cells do not secrete Hsp90 $\alpha$ in the absence of tissue stress (31). However, when the cells encounter pathophysiological conditions, such as cancer (32), or stress cues from the environment, including hypoxia (29), heat shock $(33,34)$, reactive oxygen species (35), gamma-irradiation (36), or tissue injury-released cytokines (30), they respond by sending out, via the unconventional exosome path- 
A

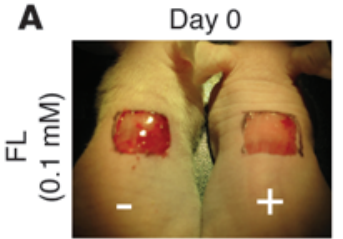

B

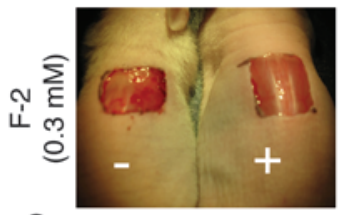

C

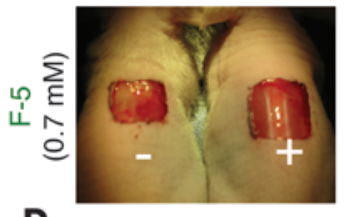

D
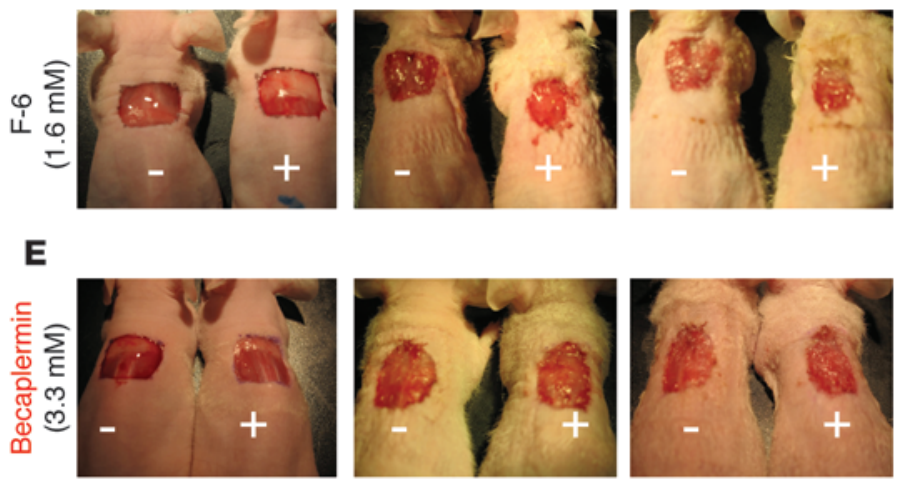

Day 4
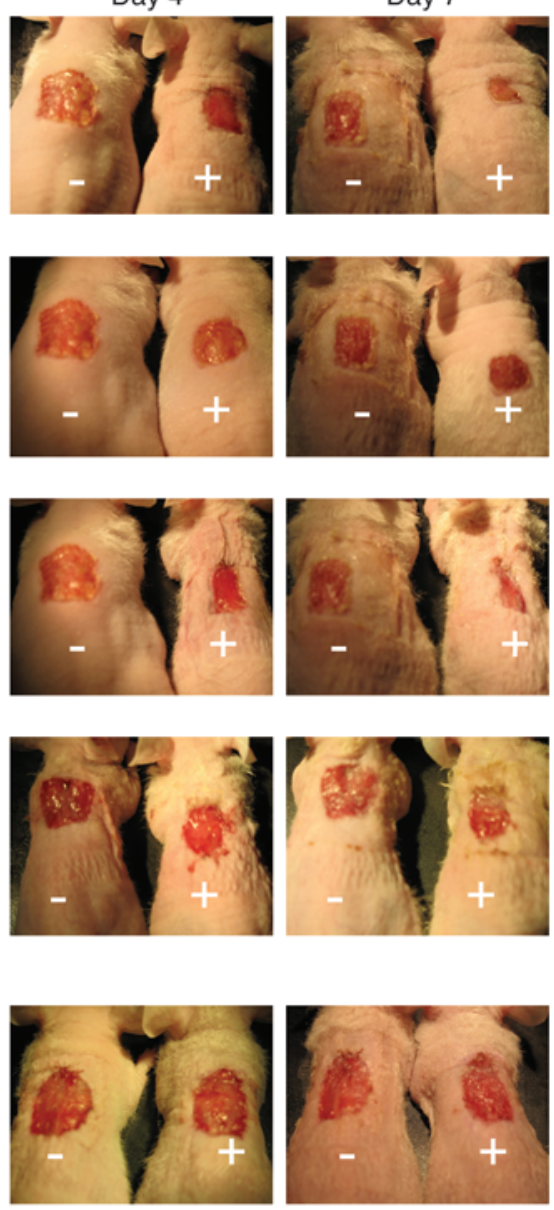
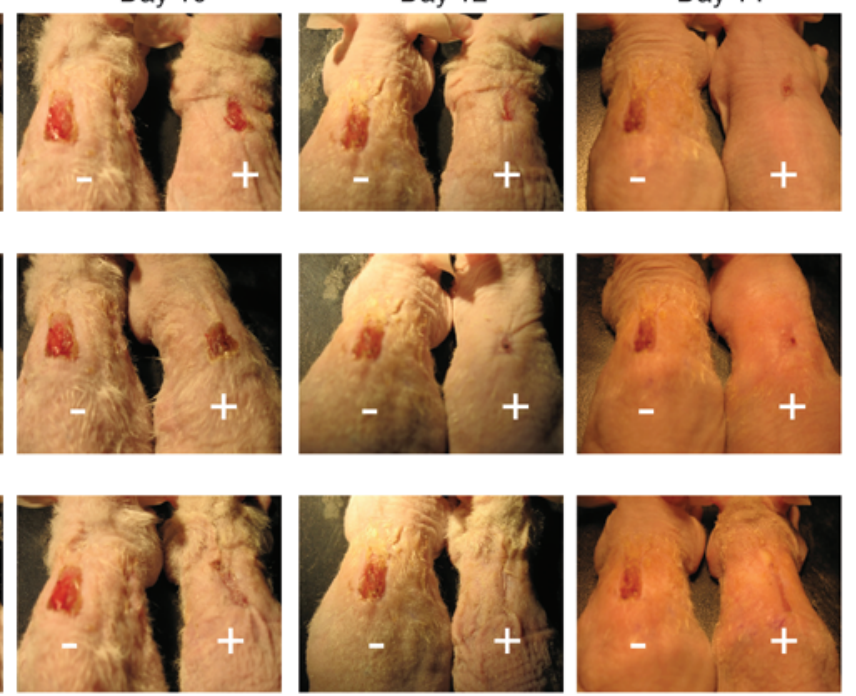
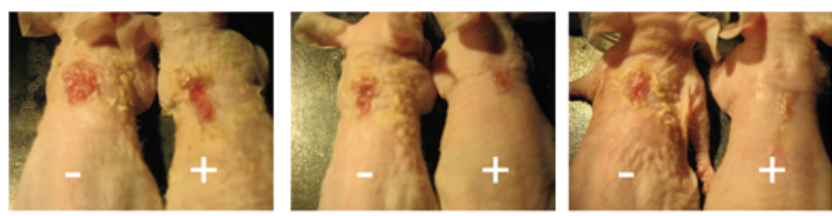

Day 10
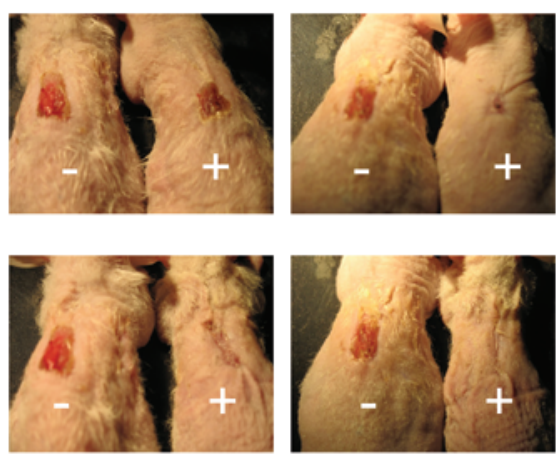

Day 12
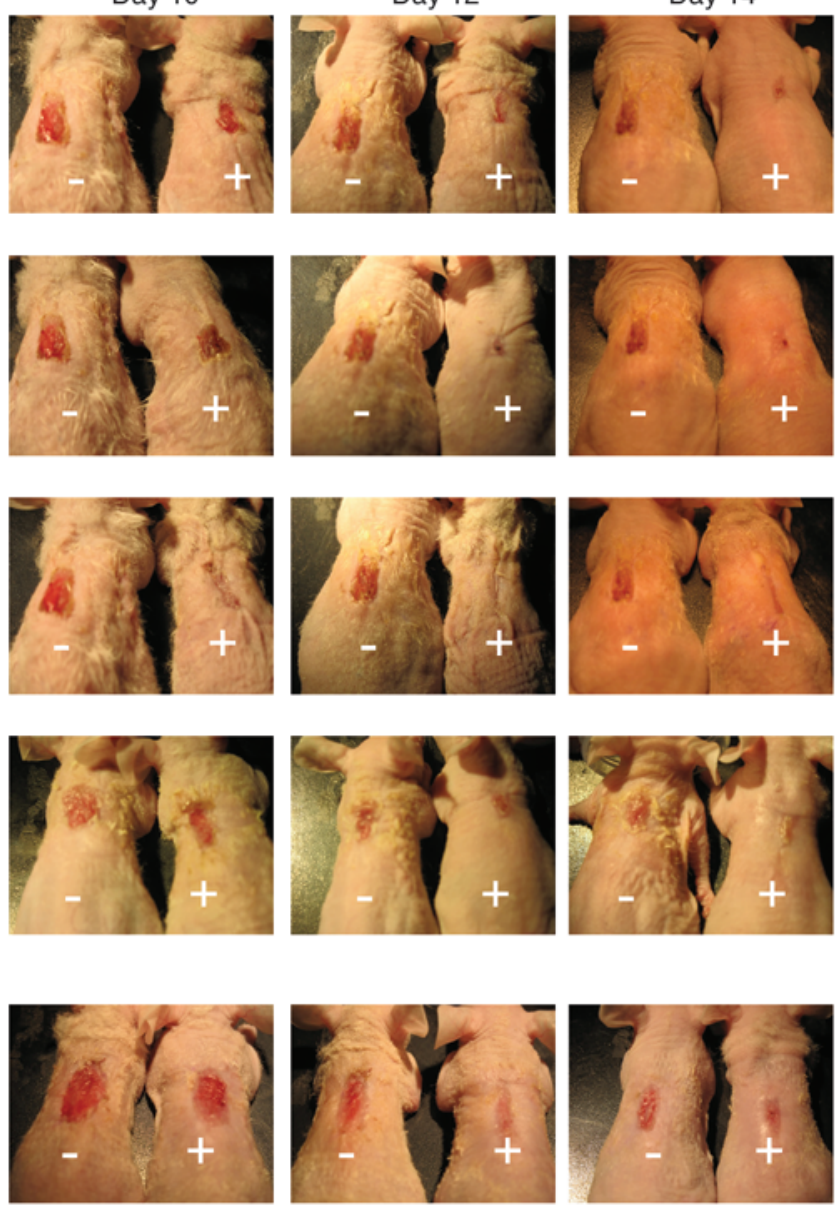

Figure 2

F-5 is superior to FDA-approved becaplermin/PDGF-BB in acute wound healing. Full-thickness skin wounds $(1 \mathrm{~cm} \times 1 \mathrm{~cm})$ in athymic nude mice were treated with either placebo (10\% CMC gel) or the gel containing an optimized concentration of (A) full-length $\mathrm{Hsp} 90 \alpha,(\mathbf{B}) \mathrm{F}-2$, (C) F-5, (D) F-6 ( $n=3$ mice per peptide, per experiment), or (E) becaplermin (100 $\mu \mathrm{g} / \mathrm{g}$ of PDGF-BB). Plus signs indicate treated mice, and minus signs indicate placebo mice. The images of 1 representative experiment are shown.

way (31), their abundantly stored $\mathrm{Hsp} 90 \alpha$ for tissue repair or tissue invasion (tumors). In this study, we take secreted Hsp90 $\alpha$ on wound healing to what we believe to be a new preclinical level by systematically analyzing secreted $\mathrm{Hsp} 90 \alpha$ treatment versus FDA-approved conventional growth factor treatment of acute and diabetic wounds in mice. More importantly, we provide 3 mechanisms to explain why a 115-aa fragment from secreted Hsp $90 \alpha$ (F-5) may represent the bona fide driving force for the initial wound closure and a new generation of treatment for diabetic wounds.

\section{Results}

Identification of a minimum promotility epitope in secreted $H s p 90 \alpha$, within its linker region and middle domain. In order to gain further insights into how secreted $\mathrm{Hsp} 90 \alpha$ heals wounds, we attempted to identify the minimum size of the therapeutic peptide in secreted Hsp90 $\alpha$ that still retains the full promotility activity of the full-length Hsp90 $\alpha$ in vitro and its full capability of promoting wound healing in vivo. Deletion mutagenesis, as schematically summarized in Figure 1A, was used to obtain the various fragments of human Hsp90 $\alpha$ largely according to its previously defined domains
(37). Recombinant proteins were produced in the pET15b protein expression system, purified sequentially by $\mathrm{Ni}^{+}$affinity column chromatography and fast protein liquid chromatography (FPLC), and confirmed on SDS-PAGE (Figure 1B). In cell motility assays, with full-length $\mathrm{Hsp} 90 \alpha$ and PDGF-BB as positive controls (Figure 1C), we found that F-2 (Figure 1D) and F-5 (Figure 1E) stimulated HDF migration as effectively as the full-length Hsp90 $\alpha$ protein (Figure 1C), although higher concentrations of F-2 and F-5 were needed. However, as the 115-aa F-5 fragment continued to shorten, we observed declines in promotility activity in those peptides. For instance, the 54-aa peptide, F-6, showed a significantly reduced promotility activity (Figure $1 \mathrm{~F}$ ). The F-1, F-3, and $\mathrm{F}-4$ peptides, which represent the $\mathrm{N}$-terminal, middle (alone), and C-terminal regions of $\mathrm{Hsp} 90 \alpha$, respectively, showed low or little stimulation of cell migration. Note that we initially reported a moderate promotility activity from both the middle and C-terminal domain fragments on HKs (30), which now appears to be due to differences in protein purity between that and the current study. Moreover, the current results were confirmed in 3 independent cell migration assays: (a) the colloidal gold migration assay that 
A

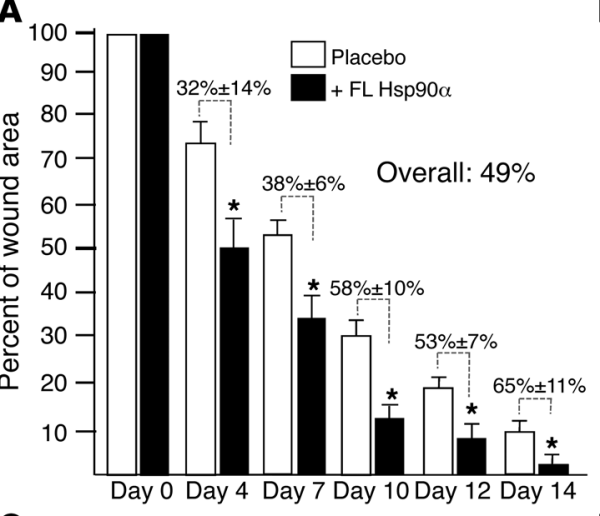

C

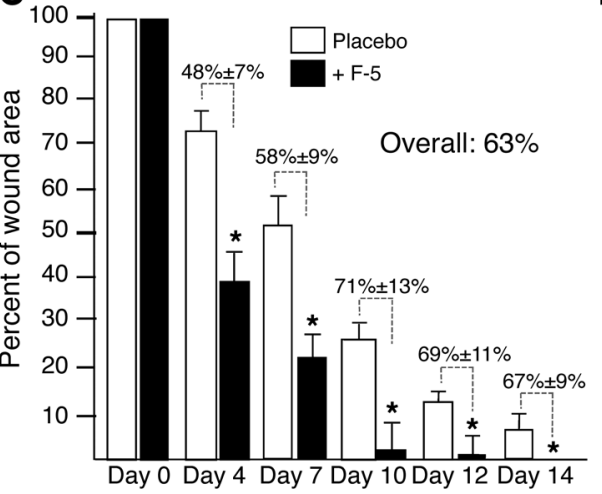

E

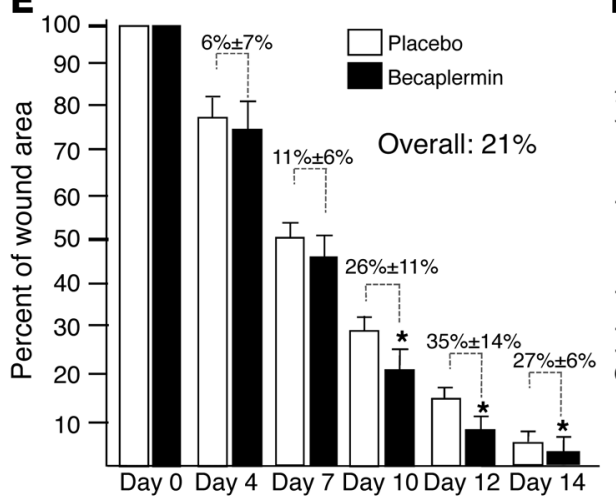

B

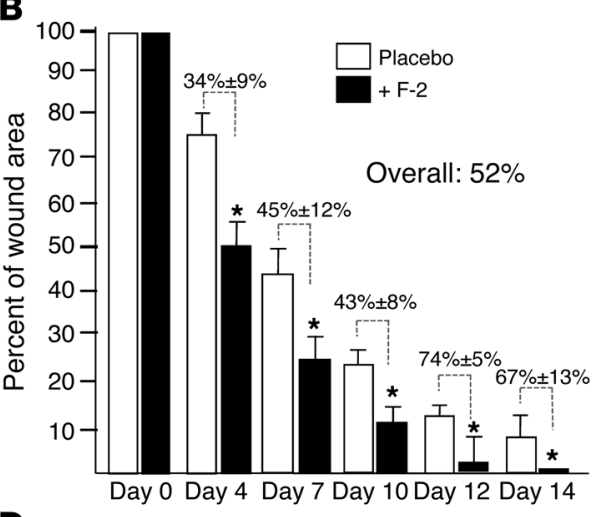

D

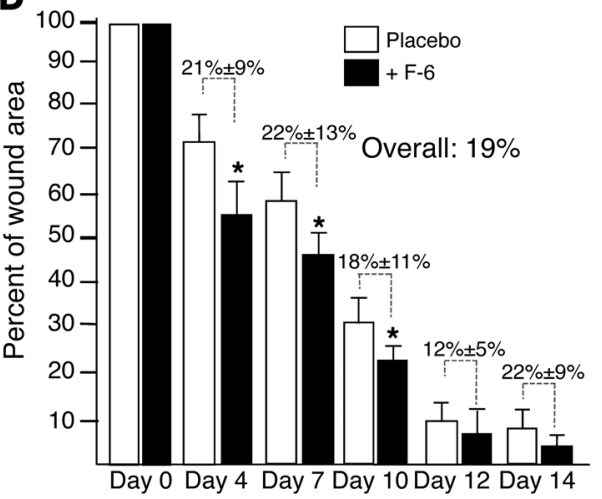

$\mathbf{F}$

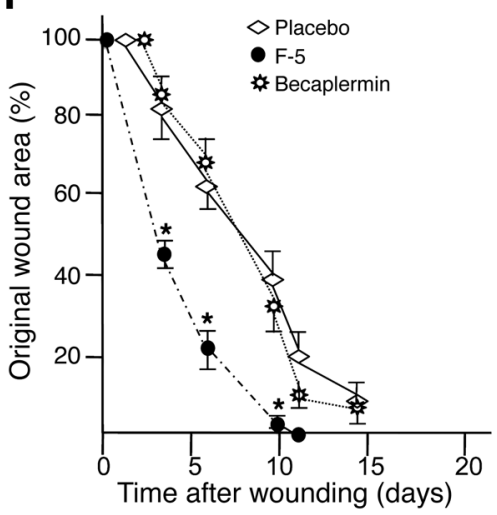

Figure 3

Measurements of F-5 versus becaplermin in acute wound healing. (A-E) Percentage of the accelerated wound closure at days $0,4,7,10,12$, and 14 after treatments of the various Hsp90o fragments or becaplermin versus placebo (mean \pm SD). (F) A single treatment with F-5 shortened the wound closure time from 17 days to 10 days. ${ }^{*} P \leq 0.05$, compared with placebo.

detects migration of individual cells; (b) the in vitro wound healing (scratch) assay that measures migration of a cell population; and (c) the transwell assay that tests 3-dimensional chemotaxis (38). Similar results were also obtained from cell migration assays with HKs and HDMECs (see below). Thus, we conclude that F-5 is the smallest peptide that retains an equivalent promotility activity as the full-length $\mathrm{Hsp} 90 \alpha$ protein.

F-5 fragment of $H$ sp $90 \alpha$ accelerates acute wound closure more strongly than becaplermin/PDGF-BB in mice. Next, we tested how these peptides translate their in vitro promotility activity to in vivo wound healing capability. In these experiments, we compared them with the only FDA-approved growth factor therapy, becaplermin gel
(PDGF-BB), in athymic hairless mice. The primary reasons to choose athymic hairless mice are (a) to minimize the host innate immune response to a human peptide and, therefore, immune response-caused wound contraction and (b) to minimize the effect of inflammatory response after the injury and to detect the specific effect of a topically applied peptide. We first carried out large-scale screening tests (4 concentrations of each peptide) in mice to identify the optimal concentration for each peptide that showed the strongest promotion of full-thickness excision wound closure after a single application on day 0 (data not shown). The peptides in their optimized concentrations were subjected to comparisons with the becaplermin gel for promoting wound closure over time. Representative images of the wounds are presented in Figure 2. Treatment with full-length Hsp90 $\alpha$ (Figure 2A), 392-aa F-2 (Figure 2B), and 115-aa F-5 (Figure 2C) all strongly accelerated the wound closure, in comparison with placebo. Among these peptides, interestingly, F-5 showed the strongest effect. In contrast, the shorter 54-aa F-6 started showing a dramatic decline in promoting wound healing (Figure 2D). Nonetheless, these in vivo results are consistent with their in vitro promotility activities. To our surprise, we found that the becaplermin gel treatment showed limited acceleration of the acute wound closure (Figure 2E). Computer-assisted planimetry of 3 independent experiments confirmed a superior effect of the Hsp $90 \alpha$ peptides to that of becaplermin gel in promoting acute wound closure (Figure 3). When promotion of wound closure was compared on the same day, it was observed that F-5 showed the strongest effect (Figure 3C vs. Figure 3, $A$ and B). F-6 (Figure 3D) and becaplermin gel (Figure 3E) showed a comparable, but significantly smaller, effect than the full-length Hsp90 $\alpha, \mathrm{F}-2$, and F-5. Using the previously described methodology (39), we also estimated the percentage of the unhealed areas of the F-5-treated wounds versus that of placebo-treated wounds on each day over that of the wounds on day 0. F-5 treatment shortened the time of complete wound closure from approximately 17 days (placebo) to 10 days (Figure 3F). We examined the possibility that multiple treatments would further shorten the time of complete wound closure. However, repeated treatments of the wounds with F-5 did not show significant advantage over a single treatment. The possible reasons, albeit technical, will be discussed (see Discussion). 


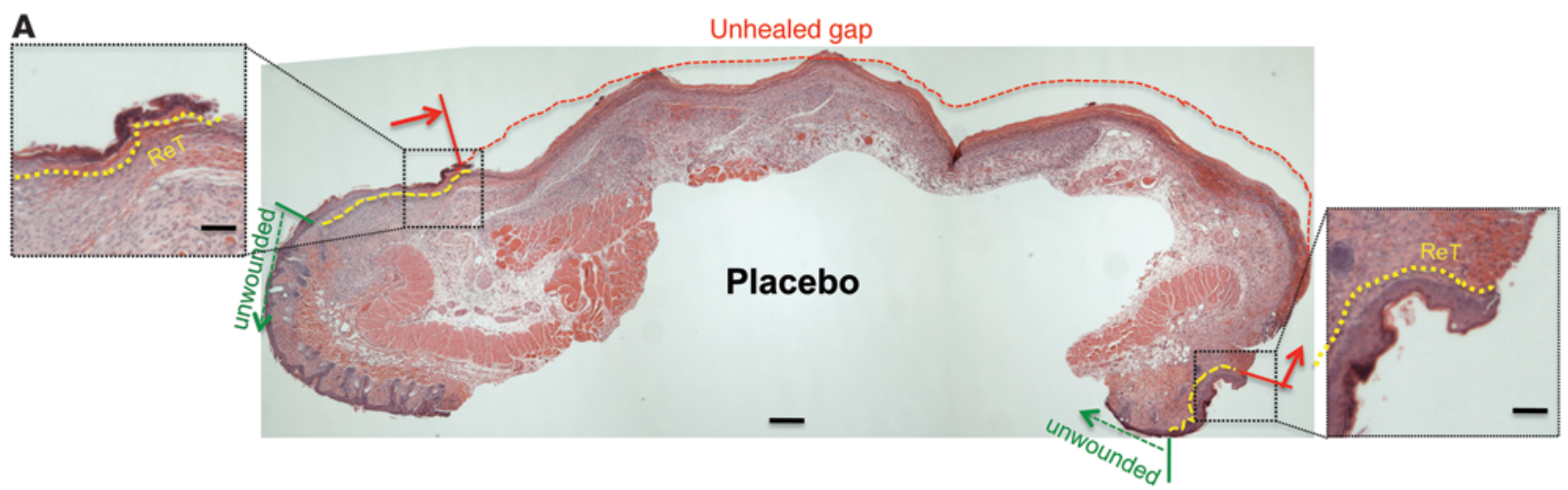

B

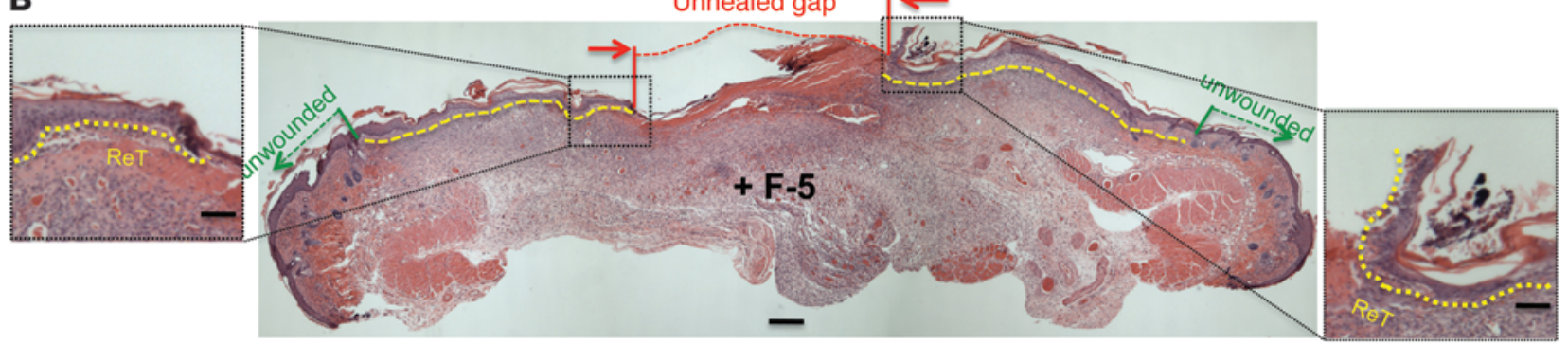

\section{Figure 4}

F-5 promotes reepithelialization of the wound. On day 7, wedge biopsies of full-thickness wounded skin (i.e., including a portion of unwounded skin), with either (A) placebo or (B) the F-5 peptide treatment, were H\&E stained and photographed under a light microscope. Independently photographed images with identical magnifications were reconstituted to show the unhealed areas of the wounds. Red dotted lines indicate unhealed wound space. Yellow dotted lines mark the newly reepithelialized epidermis. Green lines with arrows point out unwounded skin areas. The fronts of newly reepithelialized epidermis were enlarged, as shown in higher-magnification images. Scale bars: $0.33 \mathrm{~mm} ; 0.01 \mathrm{~mm}$ (left and right).

It is arguable that mouse skin wounds heal largely via contraction, due to the nature of loose skin with dense hair follicles. Whereas, human skin wounds heal through lateral migration of keratinocytes, i.e., reepithelialization, followed by inward migration of the dermal cells (40). To examine F-5-treated wounds, wedge biopsies of the day 7 wounds were subjected to H\&E staining, microscopic analyses, and measurements. The boundary between unwounded skin and newly healed skin is marked with a green arrow (Figure 4). The F-5-treated wound (Figure 4B) showed a much smaller, unhealed area overall in comparison with that of the placebo-treated wound (Figure 4A, dotted red lines). Moreover, the F-5-treated wound exhibited substantially more reepithelialization than the placebo-treated wound (Figure 4, dotted yellow lines). The reepithelialized tongue ( $\mathrm{ReT}$ ) can be clearly visualized in the enlarged images on both ends. These results suggest that promotion of reepithelialization is a mechanism of action by F-5.

$F-5$ is superior to becaplermin gel/PDGF-BB in promoting diabetic wound bealing. A critical question is whether $\mathrm{F}-5$ promotes chronic wounds as well. Among the 3 major types of chronic ulcers, pressure, venous, and diabetic ulcers, animal models are only available for studying wound healing in diabetes-equivalent conditions. Among a handful of murine models for diabetes, the $d b / d b$ mouse is a commonly used model for type II diabetes, with a plasma glucose level of $300-500 \mathrm{mg} / \mathrm{dl}$ by 6 to 8 weeks of age (in humans, $>180 \mathrm{mg} / \mathrm{dl}$ is diabetic hyperglycemia). These mice were reported to take more than 50 days to heal a $1.5 \mathrm{~cm} \times 1.5 \mathrm{~cm}$ full-thickness wound, in comparison with 20 days of similar wounds in normal littermates (41). Moreover, healed wounds in $d b / d b$ mice show a considerably higher degree of reepithelialization rather than wound contraction than that of nondiabetic mice (42). Therefore, we tested whether F-5 promotes diabetic wound healing using the $d b / d b$ mouse model. A single treatment with F-5 on day 0 led to a complete closure of the wounds between the 14th and 18th days (Figure 5A, left column), in comparison with approximately the 35 th day closure of placebotreated wounds (Figure 5A, right column). Two ways of measuring by computer-assisted planimetry were used to quantify the effectiveness of F-5. When wound closure was compared on each given day in reference to their own day 0 control wound, as shown in Figure 5B, a 50\%-90\% faster rate of wound healing was recorded for F-5 treatment over that of the placebo. When percentages of the wound closure on different days were calculated from those of the wounds on day 0, as shown in Figure 5C, F-5 shortened the time of wound closure from approximately 35 days to 14 to 18 days. H\&E staining of the day 14 wounds revealed that F-5 treatment promoted a greater degree of epidermal reepithelialization (Figure 5E) over that of placebo treatment (Figure 5D), in which ReT could be clearly seen from the enlarged images at both ends. These results show that F-5 has an even more prominent effect on diabetic wounds than acute wounds.

To confirm the H\&E results and, moreover, to analyze the endothelial cell (blood vessel formation) and myofibroblast (wound contraction) activities in wounds treated with either placebo or F-5, we carried out immunostaining assays with 3 antibodies. Anti-pan keratin antibody staining clearly revealed the ReT (Figure 6A, red lines and arrows, left panels). Anti-PECAM-1 antibody staining of the newly healed tissue showed that there was little detectable difference in the numbers of endothelial cells and blood vessels (Figure 6A, arrows) between placebo-treated 
A

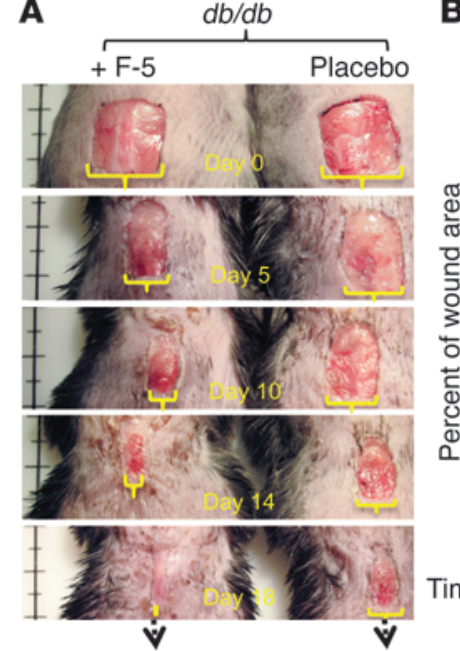

B

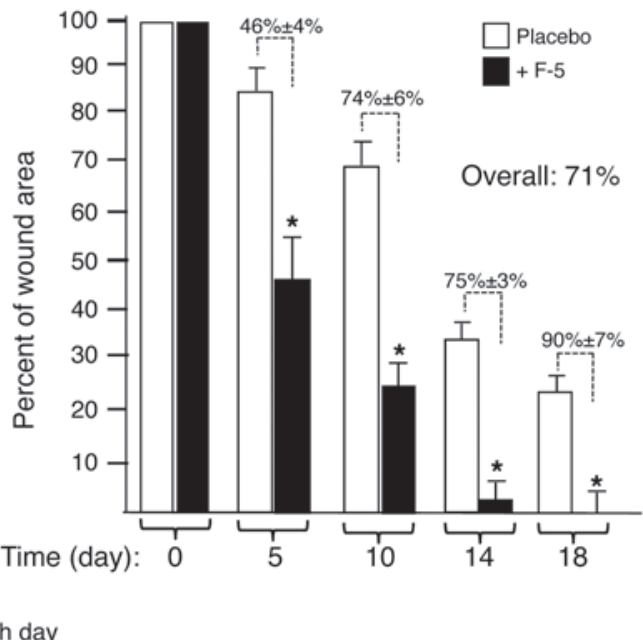

C

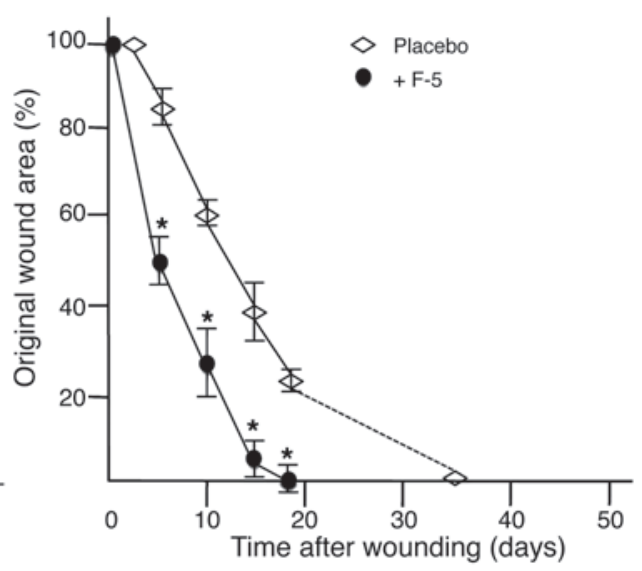

Healed on $\sim 18$ th day Healed on $\sim 35$ th day

D

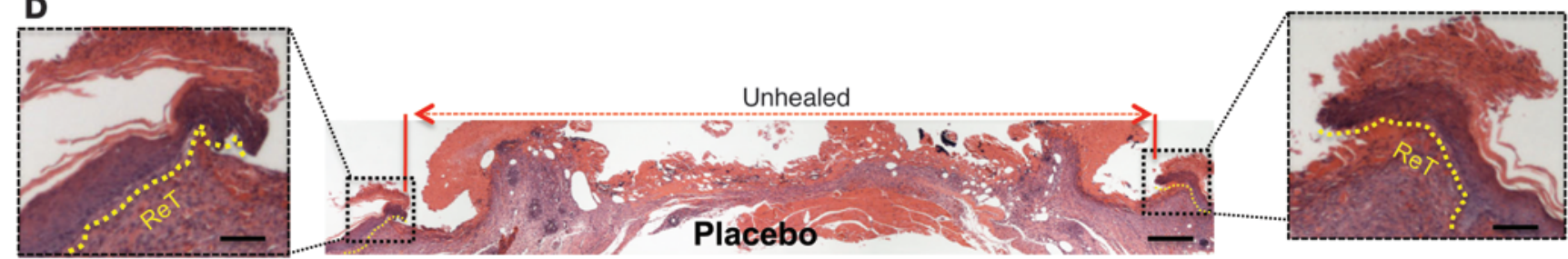

E

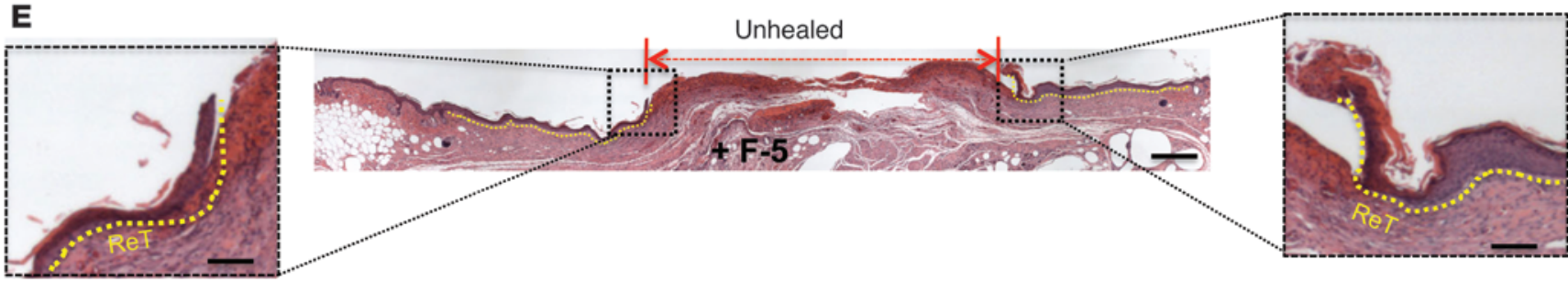

Figure 5

F-5 shortens the time in promoting diabetic wound closure by two-third. (A) Full-thickness excision wounds $(1.2 \mathrm{~cm} \times 1.2 \mathrm{~cm})$ were $\mathrm{created}$ on the backs of $d b / d b$ mice and treated with either placebo (10\% CMC gel) or the same gel containing an optimized concentration of $\mathrm{F}-5$ ( $1 \mathrm{mM})$ ( $n=3$ mice per group, per experiment). The images of 1 out of 4 representative experiments are shown from day 0 to the day of complete closure of F-5-treated wounds. (B) Percentage of the accelerated wound closure on days $0,5,10,14$, and 18, with or without F-5 treatment (mean \pm SD). ${ }^{\star} P \leq 0.05$. (C) A single treatment with F-5 on day 0 shortened the wound closure time from 35 days to 14 to 18 days. ${ }^{*} P \leq 0.05$, compared with placebo. (D and E) H\&E-stained sections of day 14 full-thickness wounds with either (D) placebo or (E) F-5 treatment were analyzed. Independently photographed images with identical magnifications were reconstituted to show the unhealed areas of the wounds. Red dotted lines with arrows indicate unhealed wound space. Yellow dotted lines mark the newly reepithelialized epidermis. The front of newly reepithelialized epidermis was enlarged to show ReT. Note that since the size of the wound biopsy was the same as that of the original wound $(1.2 \mathrm{~cm} \times 1.2 \mathrm{~cm})$, we did not expect to visualize any significant portion of the unwounded skin from the H\&E staining. Scale bars: $0.25 \mathrm{~mm}$ (D and E, center); $0.063 \mathrm{~mm}$ (D and E, left and right).

wounds and F-5-treated wounds, suggesting that F-5 does not cause any excessive recruitment of endothelial cells to the wound (Figure 6A, middle panels). Interestingly, anti-SMA antibody staining of the wounds showed visibly fewer myofibroblasts in F-5-treated wounds than in the placebo-treated wounds (Figure 6A, circles, right panels). These data suggest that F-5 promotes diabetic wound healing not by abnormally increasing wound angiogenesis or wound contraction.

While PDGF-BB was reported to cause little improvement in acute wound healing in mice (43), it accelerates wound healing in $d b / d b$ mice (39). Therefore, we made a side-by-side comparison of placebo, F-5, and becaplermin on full-thickness wound healing in $d b / d b$ mice. While becaplermin gel is recommended for daily use on diabetic ulcers in humans, we continued to use it with our single treatment protocol for the reasons previously mentioned (also see Discussion) and measured the rate of the wound closure for up to 18 days. The F-5-treated wounds showed complete closure between 14 and 18 days (Figure 6B, left panels). The placebo-treated wounds healed at a much slower rate, with more than $25 \%$ unhealed area on day 18 (Figure 6B, middle panels). Becaplermin gel treatment caused faster wound closure than the placebo (Figure 6B, right panels). However, the effect of becaplermin gel was substantially weaker than that of F-5, with a significant unhealed area on day 18. Quantitation of the data from 3 inde- 
A
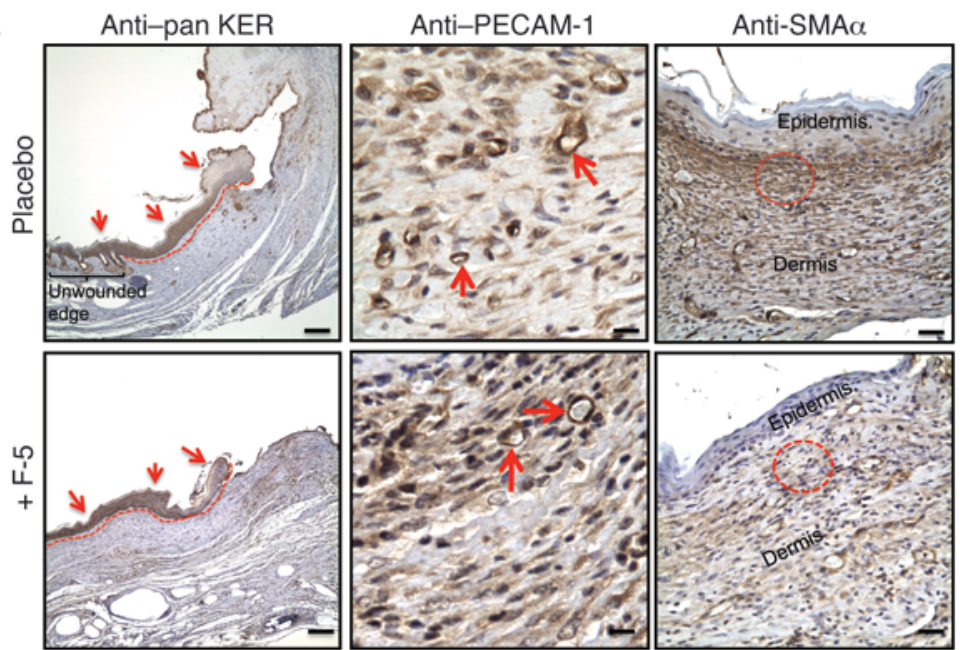

B

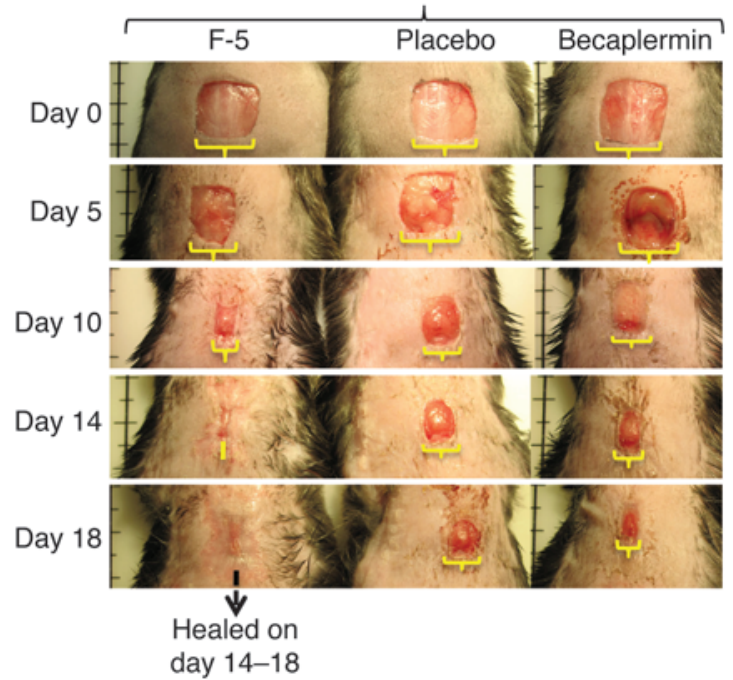

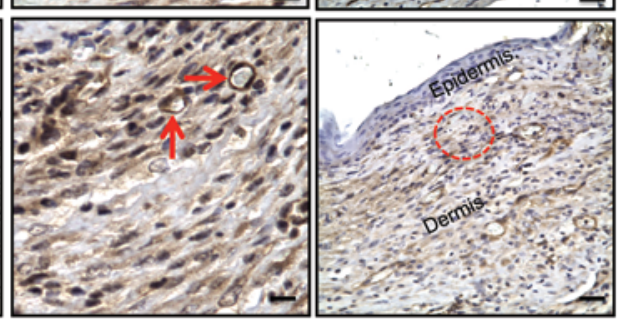

c

\section{Figure 6}

$\mathrm{F}-5$ is superior to becaplermin/ PDGF-BB in recruiting dermal cells in diabetic wound healing. (A) Immunostaining with anti-pan keratin (epidermis), anti-PECAM-1 (endothelial cells), and anti-SMA $\alpha$ (myofibroblasts) antibodies of sections of day 14 full-thickness wounds with either placebo or F-5 treatment. Nine totally randomly selected images per condition from 3 independent experiments were analyzed for consensus. The representative images are shown. Scale bars: $0.3 \mathrm{~mm}$ (left columns); $1.5 \mu \mathrm{m}$ (middle columns); $7.5 \mu \mathrm{m}$ (right columns). In the left column, arrows point to keratin-stained $\mathrm{ReT}$; in the middle column, the arrows point to sections of blood vessels; in right column, the circles point to myofibroblast staining. (B) Full-thickness excision wounds $(1.2 \mathrm{~cm} \times 1.2 \mathrm{~cm})$ were created on the backs of $d b / d b$ mice and treated with placebo (10\% CMC gel) or F-5 or becaplermin. The images of 1 out of 3 representative experiments are shown from day 0 and the day of complete closure of the F-5-treated wounds. (C) Percentage of the wound closure on day 5 to day 18 in reference to the day 0 wounds (mean $\pm S D$ ). A single treatment with $\mathrm{F}-5$ on day 0 shortened the wound closure time from approximately 35 days to 14 days. ${ }^{*} P \leq 0.05$, compared with placebo. pendent experiments is shown in Figure 6C. We conclude that F-5 is a more effective agent for both acute and diabetic wounds than conventional growth factor therapy in mice.

Three unique properties of F-5 - a common motility factor, a TGF- $\beta$ resistant factor, and a byperglycemia-resistant factor - and all absent from conventional growth factors. Having demonstrated the superior effect of the F-5 fragment in secreted Hsp90 $\alpha$ over that of FDAapproved conventional growth factor therapy on both acute and diabetic wound healing, we asked what made F-5 more effective than conventional growth factors, such as PDGF-BB. First, we reasoned that, ideally, a single factor-based wound healing agent should be a molecule that is able to recruit both epidermal and dermal cells into the wound bed. In contrast, if an agent only selectively acts on some, but not all, the skin cell types, it might be less effective in the wound healing process that requires multiple cell types of wound healing. Thus, we analyzed the effect of F-5 on migration of the 3 major human skin cell types, HKs, HDFs, and HDMECs. In the absence of any stimulus, all 3 types of skin cells exhibited limited levels of motility (Figure 7A, first column). Interestingly, PDGF-BB was only able to promote migration of HDFs but not HKs or HDMECs (Figure 7A, second column). In contrast, F-5 was able to promote migration of all 3 types of cells
(Figure 7A, third column). A computer-assisted quantitation of the cell migration is shown in Figure 7B (bars 4-9 vs. bars 1-3). Thus, the first unique property of F-5 is that it is a common promotility factor for skin cells.

What is the molecular basis for the difference between F-5 and PDGF-BB? We focused on the presence or absence of the receptors for PDGF-BB (i.e., PDGFR $\alpha$ and PDGFR $\beta$ ) and secreted Hsp90 $\alpha$ (i.e., LDL receptor-related protein-1 [LRP-1]). We found out that the lack of response to PDGF-BB from HKs and HDMECs was due to the total absence of both PDGFR $\alpha$ and PDGFR $\beta$ on these cells (Figure 7C). As expected, only HDFs expressed the 2 PDGFRs. In contrast to the selective expression of PDGFRs in HDFs, HKs, HDFs, and HDMECs all express comparable levels of LRP-1, the receptor for secreted Hsp $90 \alpha$ signaling to promote cell motility $(30,44)$. If we extrapolate these in vitro findings to equivalent wound healing events in mice, it suggests that PDGF-BB cannot have a direct role in recruitments of HKs for wound reepithelialization and HDMECs for wound neovascularization.

Second, we have previously shown that TGF- $\beta 3$ that is present in human serum (the main soluble environment of an acute wound) selectively blocks growth factor-induced HDF and HDMEC migration, due to the higher levels of T $\beta$ RII expression on these der- 
A
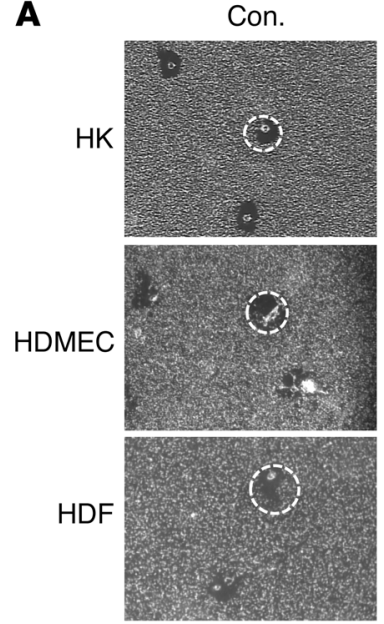

B
PDGF-BB
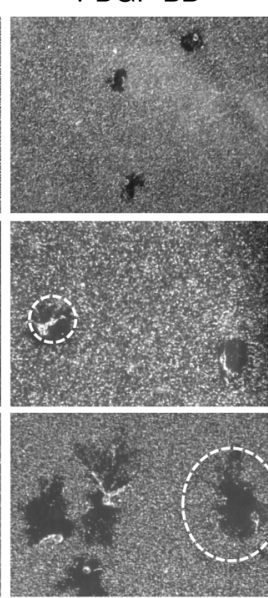

.

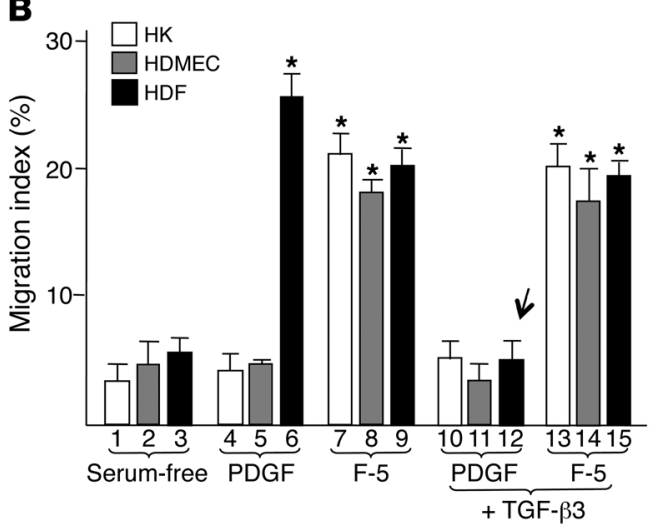

F-5
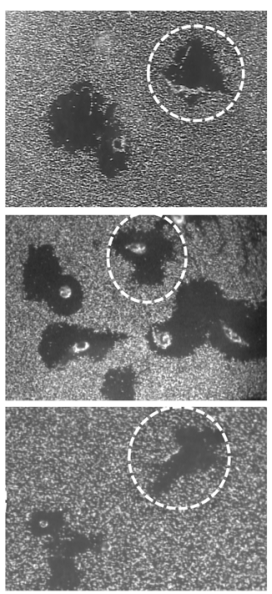

C
PDGF + T $\beta 3$
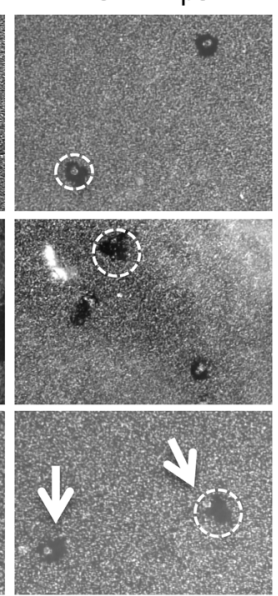

C
$\mathrm{F}-5+\mathrm{T} \beta 3$
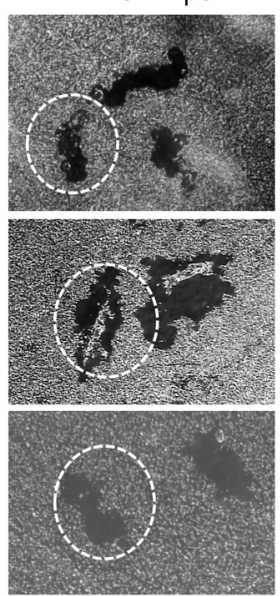

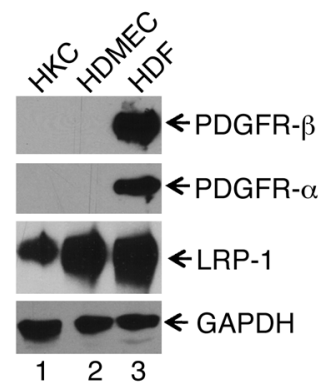

123

\section{Figure 7}

F-5 is a common promotility factor and overrides inhibition by TGF- $\beta$. Primary HKs, HDMECs, and HDFs were serum-starved overnight and subjected to colloidal gold migration assays and either untreated or treated with indicated growth factors (15 ng/ml of PDGF-BB) or F-5 (2.3 $\mu \mathrm{M})$ in the absence or presence of TGF- $\beta 3(1.5 \mathrm{ng} / \mathrm{ml})$. (A) Comparisons of F-5 peptide with PDGF-BB on stimulation of HK, HDMEC, and HDF migration in either the absence (second and third columns versus the first column) or presence (forth and fifth columns) of TGF- $\beta 3$ ). Images of cell migration from 1 representative experiment are shown. The dotted circles point out the averaged migration tracks under indicated conditions. The arrows point to cell migration inhibited by the presence of TGF- $\beta 3$. Original magnification, $\times 40$. (B) Migration index of the tracks is shown $\left(n=3\right.$; ${ }^{*} P<0.05$, compared with serum-free control). Arrow indicates T $\beta 3$-inhibited cell migration. (C) Lysates of HKs, HDMECs, and HDFs were analyzed by Western blot with anti-PDGFR $\alpha$, anti-PDGFR $\beta$, or anti-LRP-1 antibodies as indicated. Equal sample loading control is indicated by anti-GAPDH antibody blot.

mal cells than the epidermal cells (28). This finding suggests that conventional growth factors might not even be able to recruit the dermal cells to the wound, which contains an abundant amount of TGF- $\beta$ throughout the healing process. Therefore, we tested whether or not F-5 could override the inhibition of TGF- $\beta$ to promote dermal cell migration. In the presence of TGF- $\beta 3$, the PDGF-BBinduced migration of HDF was completely inhibited (Figure 7A, forth column, arrows). Intriguingly, however, even in the presence of TGF- $\beta 3$ (Figure 7A, far right column), F-5 remained equally effective on stimulation of migration of all 3 cell types. Quantitation of these results is shown in Figure 7B (bars 10-15). This second unique property of $\mathrm{F}-5$ provides another explanation for why F-5 heals wounds faster than becaplermin.

Third, we asked what made F-5 more effective in promoting diabetic wound healing. It is known that all forms of diabetes are characterized by chronic hyperglycemia in circulation, which is blamed for delayed healing of diabetic wounds (44). Reportedly, hyperglycemia was able to destabilize HIF- $1 \alpha$ protein (45), the key regulator of
Hsp90 $\alpha$ secretion in HKs and HDFs $(29,46)$. We specifically tested whether hyperglycemia blocks hypoxia-induced HDF motility and whether F-5 is able to bypass the blockage of hyperglycemia and rescue HDF migration. Hypoxia strongly promoted HDF migration under normal glucose ( $5 \mathrm{mmol} / \mathrm{l})$ medium, and hypoxia plus F-5 showed a slightly higher stimulation of cell migration (Figure 8A, top row). However, hypoxia failed to do the same under hyperglycemia (25 mmol/l glucose) (Figure 8A, middle bottom panel). We also found that hyperglycemia even blocked PDGF-BB-stimulated HDF migration (data not shown). However, the addition of F-5 "rescued" the cell migration under hyperglycemia (Figure 8A, bottom right panel). Quantitation of the migration data is shown in Figure 8B. This finding provides the third explanation for why F-5 showed a stronger effect on accelerating diabetic wounds healing.

The secreted Hsp90 action is essential for normal wound healing. We undertook 2 steps to study the critical question of whether secretion of Hsp90 $\alpha$ in wounds is intrinsically required for wound healing. First, to prove the universal importance of LRP-1 in mediating 
A
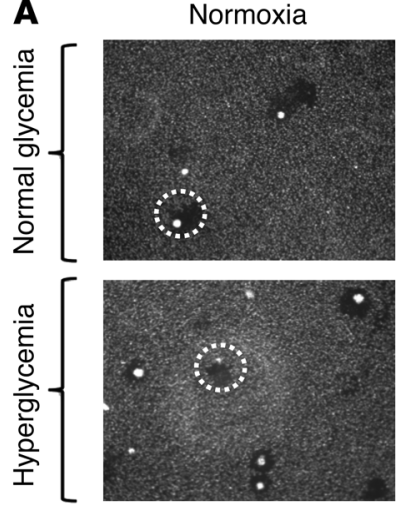

Hypoxia
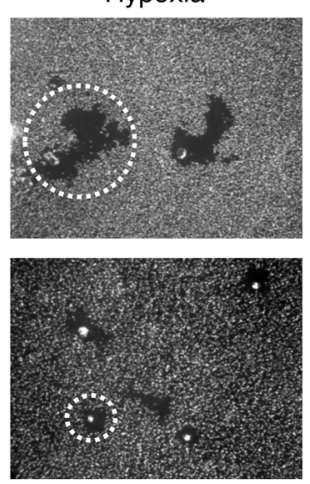

Hypoxia + F-5
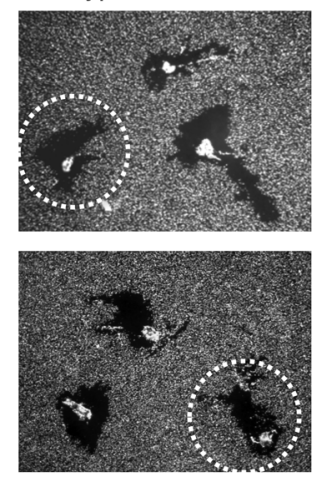

B

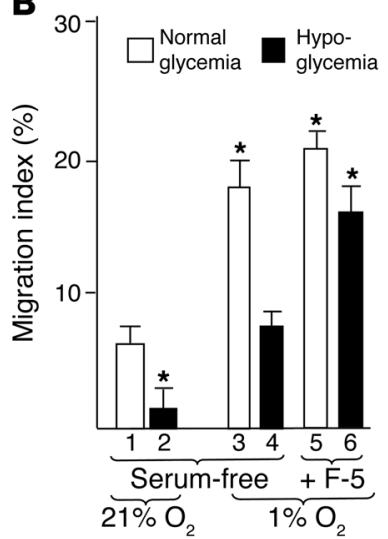

Figure 8

F-5 rescues cell migration under hyperglycemia. (A) Primary HDFs were cultured in medium containing either 5 mmol/l glucose (normal glyce$\mathrm{mia}$ ) or $25 \mathrm{mmol} / \mathrm{l}$ glucose (hyperglycemia) for 2 weeks, serum-starved overnight, and subjected to colloidal gold migration assay under either normoxia $\left(21 \% \mathrm{O}_{2}\right)$ or hypoxia $\left(1 \% \mathrm{O}_{2}\right)$ in the presence or absence of $\mathrm{F}-5(2.3 \mu \mathrm{M})$. Images of cell migration from 1 representative experiment are shown. The circles point out the averaged migration tracks under the indicated conditions. Original magnification, $\times 40$. (B) Migration index of the cell migration tracks is shown $\left(n=3 ;{ }^{*} P<0.05\right.$, compared with serum-free control).

F-5 signaling in HKs, HDFs, and HDMECs, we used the lentiviral shRNA delivery system, FG-12, to permanently downregulate LRP-1 $(30,46)$. The FG-12 system, as shown in Figure 9A, offered a more than $95 \%$ gene transduction efficiency in these cell types, as indicated by expression of a GFP gene in the same vector (but under a CMV promoter) that also carries the shRNA (under a U-6 promoter). This system enabled us to achieve nearly complete downregulation of LRP-1 proteins in all 3 types of cells (Figure 9B, lanes 2 vs. lanes 1 ). In the absence of LRP-1, all 3 types of cells were no longer able to migrate in response to F-5 stimulation, in comparison with the cells infected with a control empty vector (Figure 9C, bars 7-9 vs. bars 4-6). The blockage of F-5-induced motility is specifically due to LRP-1 downregulation, since a mini-LRP-1 receptor was able to rescue the migration of endogenous LRP-1-downregulated cells, as we previously reported $(30,46)$.

The above results provided us with a target, LRP-1, and to further investigate the importance of the "secreted Hsp90a-LRP-1" signaling in normal (acute) wound healing in vivo, we took advantage of LRP-1-associated protein (RAP), which binds to the extracellular domain of LRP-1 and blocks LRP-1 signaling (47). We chose to use day 5 acute wounds to test the effect of RAP, since (a) the most prominent effect of F-5 was detected between days 4 and 7 and (b) the effectiveness of a single treatment may decrease over time. Topically applied F-5 strongly promoted wound healing in nude mice by day 5 (Figure 9D, left panels, arrows), consistent with previous observations. In contrast, the addition of purified RAP protein dramatically delayed the naturally occurring acute wound healing process (Figure 9D, right panels, arrows). Quantitation of these data is shown in Figure 9E, which clearly revealed the delayed wound healing by RAP (Figure 9E, bar 8). This finding indicates that the LRP-1 signaling plays a critical role in normal wound healing.

\section{Discussion}

For more than 3 decades, the conventional wisdom has been that serum factors - collectively called growth factors - represent the primary force in Mother Nature's design for wound healing $(6,7,48)$. These often cell-type-specific growth factors either appear only when tissue is wounded or rise significantly from their basal concentrations in response to injury, such as TGF- $\alpha$ and KGF (FGF7) for HKs, PDGF-BB for HDFs, and VEGF-A for HDMECs. Since the mid 1970s, more than 30 growth factors have been subjected to extensive in vitro, preclinical, and clinical studies alone or in combinations (5). Despite enormous efforts, in vivo functions for many of these growth factors remained unconfirmed, and their efficacy in human trials fell short of providing significant clinical benefits $(4,6)$. These rather unexpected statistics argue against the long-standing paradigm that growth factors are the critical driving force of wound closure. We speculated that there must be fundamental reasons underlining the ineffectiveness of conventional growth factors in wound healing. We have since undertaken 2 mutually complementary approaches to (a) examine the physiological barriers for conventional growth factor actions and (b) identify a new generation of wound healing factors. In this study, we have provided several lines of evidence for why conventional growth factor therapies, such becaplermin/PDGF-BB, could not have been as effective as they were hoped to be. First, not all skin cell types express a common receptor for a given growth factor. For example, HKs and HDMECs completely lack the PDGFR and, therefore, do not respond to becaplermin. Second, the abundant presence of the TGF- $\beta$ family cytokines throughout the early phase of wound healing blocks any growth factor-stimulated migration of the dermal cells (note, not epidermal cells; see ref. 28) and, therefore, their recruitment into the wound bed $(28,49-53)$. Third, additional pathophysiological conditions, such as hyperglycemia in diabetes, add layers that block the effectiveness of growth factors in diabetic wounds $(44,45)$. More importantly, we have identified a more effective wound healing agent, F-5, a fragment from secreted Hsp90 $\alpha$. In contrast to conventional growth factors, F-5 equally promotes migration of all 3 types of human skin cells that are essential for wound healing; F-5 overrides the inhibition of human dermal cell migration by TGF- $\beta$; and F- 5 resists hyperglycemia to promote cell migration. Topical treatment of acute and diabetic wounds with F-5 greatly accelerates wound closure through increased reepithelialization. Based on these findings, we propose a new paradigm for what drives epidermal and dermal cell migration 
A

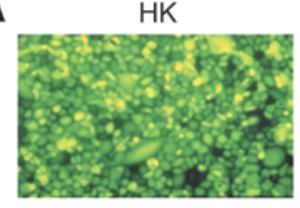

FACS:
$99 \%$

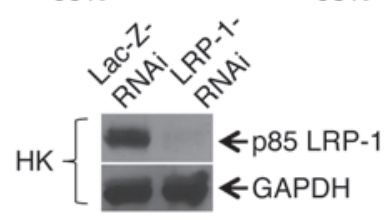

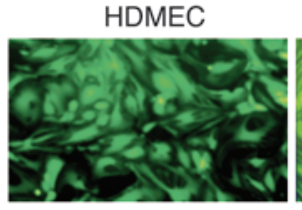

$95 \%$

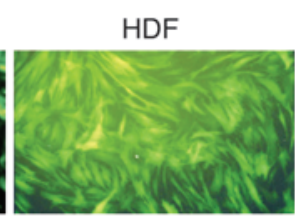

$97 \%$

B
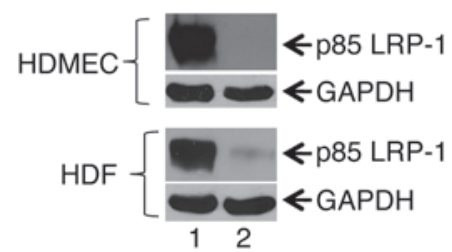

C

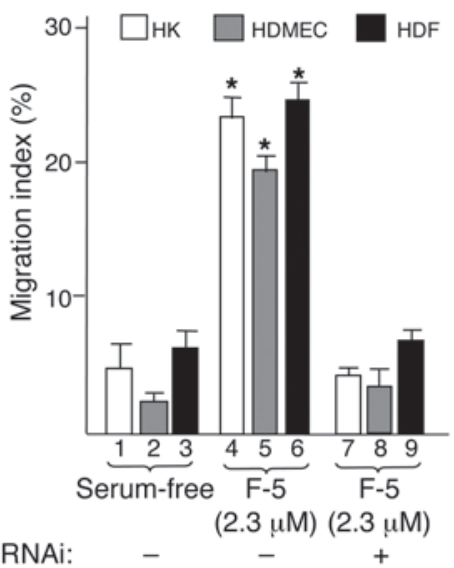

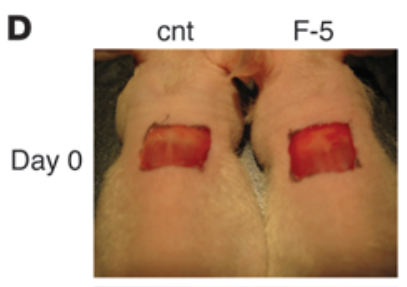

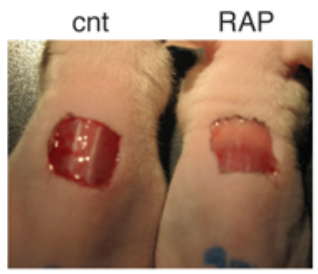

Day 5
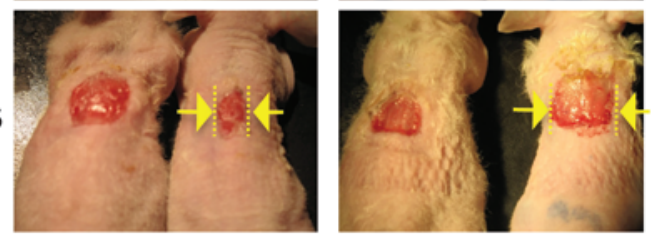

LRP-1-RNAi:

$+$

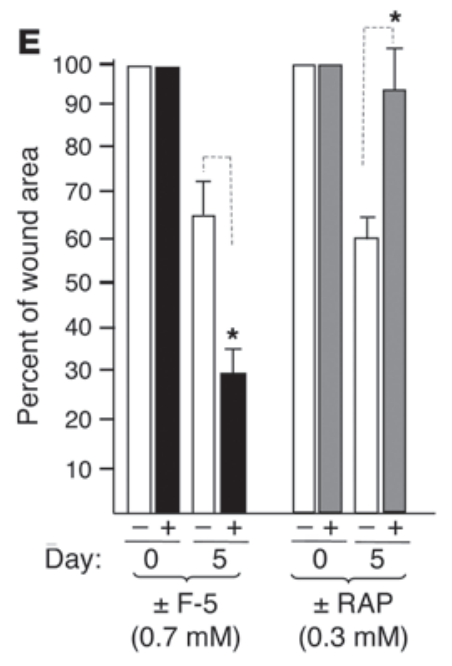

Figure 9

Hsp90 $\alpha$-LRP-1 signaling is critical to skin cell migration in vitro and wound healing in vivo. (A) A more than $95 \%$ lentiviral gene transduction efficiency is achieved by lentiviral infection, as indicated by GFP expression in HKs, HDMECs, and HDFs and quantified by FACS analysis. Original magnification, $\times 40$. (B) The same vector-mediated shRNA expression and downregulation of endogenous LRP-1 was confirmed by anti-LRP-1 antibody blot (A, C, and E; lanes 2 versus lanes 1). (C) Parental (bars 1-6) and LRP-1-downregulated (bars 7-9) HKs, HDMECs, and HDFs were subjected to colloidal gold migration assays in response to F-5. The migration was quantitated as migration index $(n=3$, ${ }^{*} P$ 5 0.03). (D) Full-thickness skin wounds $(1 \mathrm{~cm} \times 1 \mathrm{~cm})$ in athymic nude mice $(n=3$ mice per peptide, per experiment) were treated with either the vehicle containing optimized concentration of F-5 $(1 \mathrm{mM})$ or F-5 plus RAP $(0.3 \mathrm{mM})$ or vehicle alone. Images of 1 representative experiment are shown here. (E) Percentage of the wound size at days 0 and 5 of F-5- or RAP-treated wounds versus that of vehicle-treated wounds (mean \pm SD). ${ }^{*} P \leq 0.05$, compared with vehicle-treated.

to close the wound, as schematically shown in Figure 10. Prior to injury, cell motility remains undetected in intact skin (Figure 10, step 1). Within hours after skin injury, HKs start to migrate laterally across the wound (possibly induced by hypoxia-driven Hsp90 $\alpha$ autocrine signaling or TGF- $\alpha$; see ref. 44) and to secrete Hsp90 $\alpha$. At the same time, however, HDFs and HDMECs at the wound edge are not able to immediately move into the wound bed due to the presence of TGF- $\beta 3$ (Figure 10, step 2). Once the secreted Hsp90 $\alpha$ reaches the threshold concentration of $100 \mathrm{nM}(29,30)$, it triggers the dermal cells to migrate into the wound bed from the surrounding wound edge, even in the presence of TGF- $\beta 3$ (Figure 10, step 3). Finally, the migrating HKs completely close the wound, and the newly moved-in HDFs start to remodel the wounded tissue and HDMECs to rebuild new blood vessels. We propose here that injury-induced secretion of
Hsp90 $\alpha$, instead of the conventional growth factors, is the initial driving force of wound closure. After the initial wound closure, the dermal remodeling neovascularization processes would take many months to complete. Many other factors, including conventional growth factors, may play roles in the later events of wound healing, when the TGF- $\beta$ levels decrease (54).

The capability of F-5 to strongly accelerate diabetic wound closure is consistent with previous studies on a recognized cause for diabetic wounds, hyperglycemia. One of the critical environmental stimuli for wound healing is relative hypoxia (54-57). HIF-1 $\alpha$ is a master transcription factor that regulates tissue adaptive responses to environmental hypoxia (58) and is expressed throughout the multistage processes of acute wound healing. Impaired response, i.e., lack of HIF- $1 \alpha$ accumulation in the cells, to hypoxia in diabetic ulcers is 


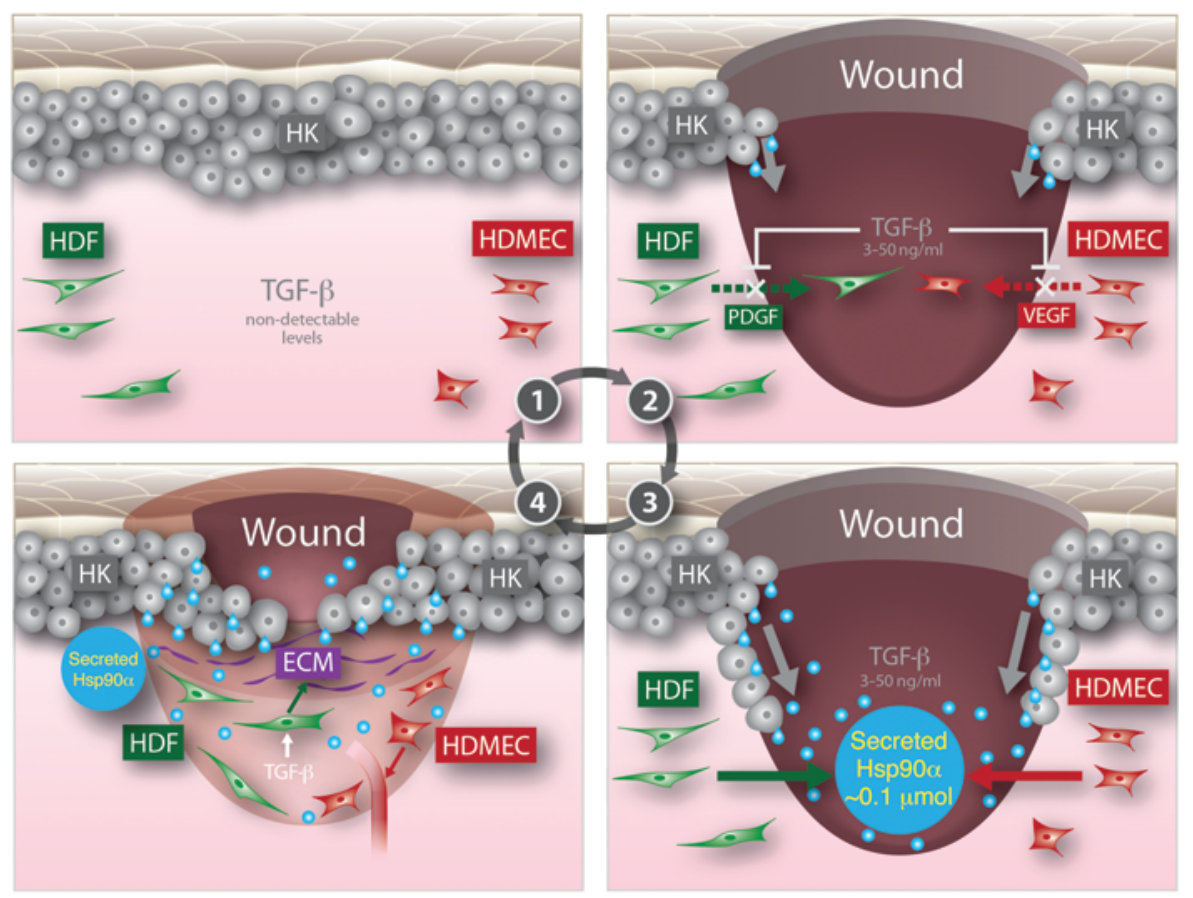

\section{Figure 10}

A model of how released Hsp90 $\alpha$, but not conventional growth factors, promotes reepithelialization and recruits dermal cells into the wound during wound healing. Step 1 shows uninjured, intact skin with little detectable TGF- $\beta$, cell migration, or stress, and step 2 shows that injury triggers release of TGF- $\beta$ from several sources, the immotile to motile transition of keratinocytes, and release conventional growth factors. However, the growth factors will not be able to recruit the dermal cells at the wound edge to the wound bed due to the presence of TGF- $\beta$. Step 3 shows that when the keratinocytes are migrating, they release/secrete Hsp90 $\alpha$. When the secreted Hsp90 $\alpha$ reaches the threshold concentration of $>0.1 \mu \mathrm{M}$, it will drive inward migration of HDFs and HDMECs. Step 4 shows that the HKs are about to close the wound and the movedin HDFs will start to remodel the wound and HDMECs to build new blood vessels. a known contributor to the delayed wound healing (45). In vivo, lower levels of HIF-1 $\alpha$ protein were reported in foot ulcer biopsies in patients with diabetes (59). In vitro studies showed that hyperglycemia impairs HIF- $1 \alpha$ protein stability and function via the von Hippellindau pathway $(45,59-61)$. Botusan et al. have demonstrated that forced stabilization of HIF-1 $\alpha$ was necessary and sufficient to resume diabetic wound healing (45). In parallel, we have previously shown that HIF- $1 \alpha$ is a key upstream regulator of Hsp90 $\alpha$ secretion. The secreted Hsp90 $\alpha$ in turn promotes human epidermal and dermal cell migration via a novel "HIF- $1 \alpha>\mathrm{Hsp} 90 \alpha$ secretion > LRP-1" signaling pathway $(29,46)$. Results of these 2 previously unrelated studies together point out the possibility that hyperglycemia destabilizes HIF-1 $\alpha$, blocks hypoxia-driven Hsp $90 \alpha$ secretion and delays diabetic wound healing. The addition of F-5 bypasses the hyperglycemia-caused damage at HIF- $1 \alpha$ and jump-starts migration of the cells that otherwise cannot respond to the environmental hypoxia.

Our data indicated that F-5 is more effective than the full-length Hsp90 $\alpha$ in vivo, but requires higher concentrations to maintain that effect. Our current understanding of this phenomenon is largely at the level of speculation. It is conceivable that without possibly steric interferences by the 235-aa N-terminal domain and the 381-aa C-terminal domain, F-5 can fully reveal its effect of promoting cell motility. On the other hand, without the $\mathrm{N}$-terminal and C-terminal domains, the shorter peptide may compromise on binding affinity and even stability and, therefore, show the requirement for higher concentration to maintain an equivalent promotility activity as the full-length protein. Our experiments show that even a single application of F-5 could lead to a remarkable acceleration of the wound closure in $d b / d b$ mice. If both such efficacy and duration of the F-5 action could translate into humans, it may significantly improve patient life and help to reduce the overall cost of diabetic wound clinic as well. The high cost of the currently available care mostly comes from home visits by physicians with various specialties and daily passive assistance of nurses, due to unavailability of effective treatments $(51,62)$. On the other hand, we expect that multiple treatments with F-5 should result in more prominent healing effects. Becaplermin gel, for instance, is recommended for daily applications to achieve its clinical effect. In the current study, we focused on a single treatment in our animal experiments for 2 technical reasons. First, for experiments that involve a large number of mice, it is hard to ensure that the procedures on all wounds are performed universally. Second, frequent opening and closing a healing wound for new treatments will risk damaging the on-going healing tissue (the newly generated epidermal layer in particular) and add extra stress and discomfort to the animals. Nonetheless, there have been reported options to deal with these technical limitations. Covering the wound with Tegaderm and multiple applications of the tested agent by injecting it through the Tegaderm with a gauge needle was reported as a way to minimize these technical concerns (63).

The fact that extracellular Hsp90 $\alpha$ is a motogen but not a mitogen (i.e., it does not stimulate cell proliferation) makes physiological sense $(29,30)$. First, keratinocyte migration occurs almost immediately after skin injury and plays a critical role in closing the wound. After the initial epidermal closure, completion of the subsequent dermal neovascularization and remodeling processes would take many months. Second, when a cell is migrating toward the wound area, it cannot proliferate at the same time. In addition, growth factor-stimulated proliferation of both epidermal and dermal cells would be inhibited by TGF- $\beta$ that appears in the injured skin (28). Third, cell migration precedes cell proliferation during wound healing. While the cells at the wound edge are moving toward the wound bed, they leave behind "empty space" between themselves and the cells behind them. The cells that are located behind the migrating cells start to proliferate after losing contact inhibition with the front moving cells. The stimuli of the cell proliferation likely come from plasma growth factors in the surrounding unwounded blood vessels, in which TGF- $\beta$ levels are low or undetectable. Thus, cell proliferation appears to refill the space generated by the front-migrating cells. The role of secreted Hsp90 $\alpha$ appears to promote the initial wound closure as quickly as possible. 
Finally, proof of the relevance of animal model research to humans is the ultimate standard, especially considering the fact that many animal models for human diseases do not exactly reflect the genetic setting in humans. Many believe that this is the main reason for the majority of the therapeutic agents in the past, which show great promise in animal studies, to have ultimately failed in humans. For instance, human diabetes is a polygenic disease, whereas the $d b / d b$ mouse is a monogenic (i.e., mutation in a single gene) diabetic model. Therefore, whether or not F-5 has similar effect on human diabetic wounds remains to be seen.

\section{Methods}

Primary human neonatal HKs, HDFs, and HDMECs were purchased from Clonetics. HKs were cultured in EpiLife medium with added HK growth supplements. HDFs were cultured in DMEM supplemented with $10 \%$ FBS. HDMECs were cultured in growth factor-supplemented Medium 131 (Cascade Biologics). The third or fourth passages were used in cell migration assays. rhPDGF-BB, rhTGF- $\alpha$, and rhTGF- $\beta 3$ were purchased from R\&D Systems. Regranex (becaplermin $0.01 \%$ gel, Ortho-McNeil Pharmaceutical) was prescribed and purchased from USC Medical Plaza Pharmacy solely for this study. Antibodies against PDGFR $\alpha$ and PDGFR $\beta$ were from Santa Cruz Biotechnology Inc. (SC-338) and Genzyme (1263-00), respectively. Anti-LRP1/CD91 antibody was purchased from Progen Biotechnik. Mouse monoclonal antibody (pan) against Keratin (ab8068) was from Abcam Inc. PECAM-1 (M-20) goat polyclonal antibody (sc-1506) was from Santa Cruz Biotechnology Inc. Monoclonal mouse anti-mouse SMA antibody was from Dako Denmark A/S. Biotinylated rabbit antigoat IgG and biotinylated horse anti-mouse IgG were from Vector Laboratories. Chromagon system, Dako Liquid DAB+ substrate, was from Dako Denmark A/S. Mouse antibody on mouse tissues (mouseon-mouse) detection system, VECTOR M.O.M. Immunodetection Kit, and the Immunoperoxidase System, VECTORSTAIN Elite ABC Kit, were from Vector Laboratories. Carboxymethylcellulose (CMC) sodium salt (C5678) ( $\mathrm{pH}$ measured at 7.14) was from Sigma-Aldrich. Rat type I collagen was purchased from BD Biosciences. Anti- $\beta$-actin antibody and anti-GAPDH antibody were from Cell Signaling Technology. The RAP construct in bacteria was a gift of Guojun Bu (University of Washington, St. Louis, Missouri, USA). XL-10 Gold Ultra competent cells were from Stratagene. Stat Strips (adhesive bandages) were from Notro Max Products. 3M Coban (self-adhesive wrap) was from 3M.

Subcloning, production, and purification of $H s p 90 \alpha$ fragments. The cDNAs encoding the full-length and various fragments (F-1 to F-6) of Hsp90 $\alpha$ were generated by PCR using human Hsp90 $\alpha$ cDNA as the template. PCR fragments were subcloned into the His-tag pET15b vector (EMD Biosciences Inc.) at BamH1 or Bam H1 and NdeI sites. DNA sequences of the fragments were verified by DNA sequencing. The pET15b-Hsp90 $\alpha$ constructs were transformed into BL21-codonPlus (DE3)-RP competent cells (Stratagene) following a manufacturer-provided protocol. Protein production and purification were described previously (30). Proteins were confirmed by Western blots concentrated in Centricons YM (10 to 50) to a final concentration of $1 \mathrm{mg} / \mathrm{ml}$, and stored in $10 \%$ glycerol in DPBS at $-80^{\circ} \mathrm{C}$.

Cell migration assays. The colloidal gold migration assay, the in vitro wound healing (scratch) assay, and the transwell assay were as modified and described previously by us $(37,38)$. Data from independent experiments $(n \geq 3)$ were averaged and calculated as percentage, OD reading, or fold increase in response to corresponding stimulus over the baseline control (mean $\pm \mathrm{SD} ; P<0.05)$.

The FG-12 lentiviral system, RNAi against LRP-1, lentiviral production, and infection. Details regarding these methods have been published by our laboratory and by others $(29,46,63)$.

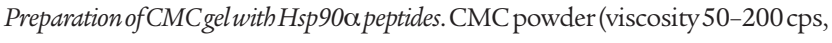
purity $99.5 \%$, sodium salt) was dissolved in double-distilled $\mathrm{H}_{2} \mathrm{O}$ in a tissue culture hood at $5 \%$ concentration $(\mathrm{w} / \mathrm{v})$, heated for 4 hours at $37^{\circ} \mathrm{C}$, placed in a shaker for 24 hours at $4^{\circ} \mathrm{C}$, and brought back to room temperature. This CMC solution was mixed in a 1:1 ratio (vol/vol) with a desired concentration of FPLC-purified and -filtered $(0.22 \mu \mathrm{m}) \mathrm{Hsp} 90 \alpha$ peptide (in DPBS). The CMC gel diluted with DPBS or mixed with DPBS containing Hsp90 $\alpha$ peptides was applied topically to the wounds.

Wound healingin mice. Thymichairless (Foxn1) mice and BKS.Cg- $\mathrm{m}+/+\mathrm{Lepr}^{\mathrm{db}} / \mathrm{J}$ mice were obtained from The Jackson Laboratory and housed 4 per cage prior to or 1 per cage during experiments. Athymic hairless mice of 8 to 10 weeks of age were anesthetized with isoflurane prior to the wound-creating surgery. Full-thickness excision wounds $(1 \mathrm{~cm} \times 1 \mathrm{~cm})$ were created by marking the area of the wound in the mid-back with a fine marker and a ruler, lifting the skin with a pair of a forceps and excising the full-thickness skin along the lines with a pair of surgical scissors. The $d b / d b$ mice of 6 weeks of age were subjected to the similar procedure (but with back shaved) to create $1.2 \mathrm{~cm} \times 1.2 \mathrm{~cm}$ wounds. Immediately after the surgery on day 0 , the wounds were topically treated with $100 \mu$ l of either $5 \%$ CMC gel (placebo) or the same gel containing an Hsp90 $\alpha$ peptide or becaplermin gel (100 $\mu \mathrm{g} / \mathrm{g}$ PDGF-BB) at its clinically recommended dosage. Each wound was covered with a bandage and a self-adherent wrap (Coban) to prevent desiccation and infection while the wound was exposed. Bandages and Cobans were changed every 3 days after the initial 4 days. Standardized digital photographs were taken of the wounds, with the same distance between camera and preanesthetized animal for each animal. The photographs were examined using planimetry for objective evaluation for degree of wound healing $(28,62)$. The open wound areas were determined with an image analyzer (AlphaEase FC version 4.1.0, Alpha Innotech Corporation). The total pixels that cover the unhealed areas were drawn onto the digital photographs using a pattern overlay in ImageJ (http://rsbweb.nih.gov/ij/). The number of pixels covering an open wound area on a given day was divided by the number of pixels spreading over the initial wound on day 0 to obtain the percentage of closure.

Percentage, rather than actual distance (e.g., $\mathrm{mm}$ ), of wound closure was calculated from the measured wound areas (pixel density). This method allows more accurate measurements of the wounds, considering the fact that certain margin of errors during surgical procedures may exist among different experimental groups or even among the 3 mice within the same group. The percentage of wound healing was based on changes in the same wound on the same mouse for indicated time points, instead of changes among different mice. Thus, the calculated mean for the wound healing (percentage) among the 3 mice in a group was independently obtained, and the statistics of 3 groups of 3 independent experiments were calculated. We defined and presented the healing in 2 ways: (a) the open area of the healing wound on a given day/the open area of the original wound $\times 100$ for the indicated days and (b) comparison between the healed area of the wounds with Hsp90 $\alpha$ treatment with the healed areas of the wounds with placebo treatment on each specific day.

HळE and IHC staining. The F-5-untreated or -treated mice were euthanized either 7 (nude mice) or 14 days ( $d b / d b$ mice) after the surgery (wounding). The wounds, together with unwounded skin margins, were excised and put into $10 \%$ formaldehyde. The H\&E staining was carried out as previously described (26). In order to show the wound of placebotreated mice compared with that of F-5-treated mice, multiple overlapping pictures were taken under a microscope (Nikon, Eclipse TE2000-U, $\times 4$ ) and used to reconstitute the entire wound (64). Standard IHC staining procedure was carried out (65). All antibodies were used in 1:100 dilutions. The M.O.M. kit was used for mouse antibodies (pan-keratin and SMA) on mouse tissues to control background staining. 
Statistics. Data are presented as mean \pm SD. Statistical significance for comparisons was determined by the Student's 2-tailed $t$ test. A $P$ value of equal or less than 0.05 was considered statistically significant (64).

Study approval. All animal studies were conducted using protocols approved, prior to initiation of this study, by the University of Southern California Institutional Animal Use Committee.

\section{Acknowledgments}

We thank Kathy Roger for initial technical help on the $d b / d b$ mouse model and Guojun Bu for the RAP construct. We thank
Rosie Kim for technical assistance in the laboratory. This study was supported by a VA Merit Award (to D.T. Woodley) and by NIH grants GM066193 and GM067100 (to W. Li), AR46538 (to D.T. Woodley), and AR33625 (to M. Chen and D.T. Woodley).

Received for publication January 19, 2011, and accepted in revised form September 7, 2011.

Address correspondence to: Wei Li, 1441 Eastlake Avenue, Room6320, Los Angeles, California 90089, USA. Phone: 323.865.0618; Fax: 323.865.0105; E-mail: wli@usc.edu.
1. Crandall MA. Wound care markets: volume I: skin ulcers. In: Heffner S, ed. Wound Care Markets. New York, New York, USA: Kalorama Information; 2003.

2. Sen CK, et al. Human skin wounds: a major and snowballing threat to public health and the economy. Wound Repair Regen. 2009;17(6):763-771.

3. Falanga V. Wound healing and its impairment in the diabetic foot. Lancet. 2005;366(9498):1736-1743.

4. Werner S, Grose R. Regulation of wound healing by growth factors and cytokines. Physiol Rev. 2003;83(3):835-870.

5. Grose R, Werner S. Wound-healing studies in transgenic and knockout mice. Mol Biotechnol. 2004, 28(2):147-166

6. Martin P. Wound healing--aiming for perfect skin regeneration. Science. 1997;276(5309):75-81.

7. Singer AJ, Clark RA. Cutaneous wound healing. NEngl J Med. 1999;341(10):738-746.

8. Brown GL, et al. Enhancement of wound healing by topical treatment with epidermal growth factor. N Engl J Med. 1989;321(2):76-79.

9. Pastor JC, Calonge M. Epidermal growth factor and corneal wound healing. A multicenter study. Cornea. 1992;11(4):311-314.

10. Ramsay HA, Heikkonen EJ, Laurila PK. Effect of epidermal growth factor on tympanic membranes with chronic perforations: a clinical trial. Otolaryngol Head Neck Surg. 1995;113(4):375-379.

11. Fernandez-Montequin JI, et al. Intralesional injections of Citoprot-P (recombinant human epidermal growth factor) in advanced diabetic foot ulcers with risk of amputation. Int Wound J. 2007; 4(4):333-343.

12. Mohan VK. Recombinant human epidermal growth factor (REGEN-D 150): effect on healing of diabetic foot ulcers. Diabetes Res Clin Pract. 2007; 78(3):405-411.

13. Greenhalgh DG, Rieman M. Effects of basic fibroblast growth factor on the healing of partial-thickness donor sites. A prospective, randomized, double-blind trial. Wound Repair Regen. 1994; 2(2):113-121.

14. Fu X, et al. Randomised placebo-controlled trial of use of topical recombinant bovine basic fibroblast growth factor for second-degree burns. Lancet. 1998;352(9141):1661-1664.

15. Uchi H, et al. Clinical efficacy of basic fibroblast growth factor (bFGF) for diabetic ulcer. EurJ Dermatol. 2009;19(5):461-468.

16. Ma B, et al. Randomized, multicenter, double-blind, and placebo-controlled trial using topical recombinant human acidic fibroblast growth factor for deep partial-thickness burns and skin graft donor site. Wound Repair Regen. 2007;15(6):795-799.

17. Robson MC, et al. Sequential cytokine therapy for pressure ulcers: clinical and mechanistic response. Ann Surg. 2000;231(4):600-611.

18. Pierce GF, Tarpley JE, Yanagihara D, Mustoe TA, Fox GM, Thomason A. Platelet-derived growth factor (BB homodimer), transforming growth factor-beta 1 , and basic fibroblast growth factor in dermal wound healing. Neovessel and matrix formation and cessation of repair. Am J Pathol. 1992; 140(6):1375-1388.
19. Steed DL. Clinical evaluation of recombinant human platelet-derived growth factor for the treatment of lower extremity diabetic ulcers. Diabetic Ulcer Study Group. J Vasc Surg. 1995;21(1):71-78.

20. LeGrand EK. Preclinical promise of becaplermin (rhPDGF-BB) in wound healing. Am J Surg. 1998;176(2A suppl):48S-54S.

21. Smiell JM, Wieman TJ, Steed DL, Perry BH, Sampson AR, Schwab BH. Efficacy and safety of becaplermin (recombinant human platelet-derived growth factor-BB) in patients with nonhealing, lower extremity diabetic ulcers: a combined analysis of four randomized studies. Wound Repair Regen. 1999;7(5):335-346.

22. Wieman TJ, Smiell JM, Su Y. Efficacy and safety of a topical gel formulation of recombinant human platelet-derived growth factor-BB (becaplermin) in patients with chronic neuropathic diabetic ulcers. A phase III randomized placebo-controlled doubleblind study. Diabetes Care. 1998;21(5):822-827.

23. Nagai MK, Embil JM. Becaplermin: recombinant platelet derived growth factor, a new treatment for healing diabetic foot ulcers. Expert Opin Biol Ther. 2002;2(2):211-218

24. Mandracchia VJ, Sanders SM, Frerichs JA. The use of becaplermin (rhPDGF-BB) gel for chronic nonhealing ulcers. A retrospective analysis. Clin Podiatr Med Surg. 2001;18(1):189-209.

25 . Bejcek BE, et al. The v-sis oncogene product but not platelet-derived growth factor (PDGF) A homodimers activate PDGF alpha and beta receptors intracellularly and initiate cellular transformation. J Biol Chem. 1992;267(5):3289-3293.

26. van den Dolder J, Mooren R, Vloon AP, Stoelinga PJ, Jansen JA. Platelet-rich plasma: quantification of growth factor levels and the effect on growth and differentiation of rat bone marrow cells. Tissue Eng. 2006;12(11):3067-3073.

27. Henry G, Li W, Garner W, Woodley DT. Human serum (but not plasma) promotes humans keratinocyte migration. Lancet. 2003;361(9357):574-576

28. Bandyopadhyay B, et al. A "traffic control" role for TGFbeta3: orchestrating dermal and epidermal cell motility during wound healing. J Cell Biol. 2006; 172(7):1093-1105

29. Li W, et al. Extracellular heat shock protein90alpha: linking hypoxia to skin cell motility and wound healing. EMBO J. 2007;26(5):1221-1233.

30. Cheng CF, et al. Transforming growth factor alpha (TGF $\alpha$ )-stimulated secretion of Hsp90 $\alpha$ : using the receptor LRP-1/CD91 to promote human skin cell migration against a TGFbeta-rich environment during wound healing. Mol Cell Biol. 2008; 28(10):3344-3358.

31. Cheng CF, Fan J, Zhao Z, Woodley DT, Li W. Secreted heat shock protein-90 $\alpha$ : a more effective and safer target for anti-cancer drugs? Curr Sign Transduct Ther. 2010;5:121-127.

32. Tsutsumi S, Neckers L. Extracellular heat shock protein 90: a role for a molecular chaperone in cell motility and cancer metastasis. Cancer Sci. 2007; 98(10):1536-1539.

33. Hightower LE, Guidon PT Jr. Selective release from cultured mammalian cells of heat-shock (stress) proteins that resemble glia-axon transfer proteins. J Cell Physiol. 1989;138(2):257-266.

34. Clayton A, Turkes A, Navabi H, Mason MD, Tabi $\mathrm{Z}$. Induction of heat shock proteins in B-cell exosomes. J Cell Sci. 2005;118(pt 16):3631-3638.

35. Liao DF, et al. Purification and identification of secreted oxidative stress-induced factors from vascular smooth muscle cells. J Biol Chem. 2000; 275(1):189-196

36. Yu X, Harris SL, Levine AJ. The regulation of exosome secretion: a novel function of the $\mathrm{p} 53$ protein. Cancer Res. 2006;66(9):4795-4801.

37. Lindquist S, Craig EA. The heat-shock proteins. Annu Rev Genet. 1988;22:631-677.

38. Li W, et al. Signals that initiate, augment, and provide directionality for human keratinocyte motility. J Invest Dermatol. 2004;123(4):622-633.

39. Greenhalgh DG, Sprugel KH, Murray MJ, Ross R. PDGF and FGF stimulate wound healing in the genetically diabetic mouse. Am J Pathol. 1990; 136(6):1235-1246.

40. Coulombe PA. Wound epithelialization: accelerating the pace of discovery. J Invest Dermatol. 2003; 121(2):219-230.

41. Olerud JE. Models for diabetic wound healing and healing into percutaneous devices. J Biomater Sci Polym Ed. 2008;19(8):1007-1020.

42. Gibran NS, et al. Diminished neuropeptide levels contribute to the impaired cutaneous healing response associated with diabetes mellitus. J Surg Res. 2002;108(1):122-128.

43. Lynch SE, Nixon JC, Colvin RB, Antoniades HN. Role of platelet-derived growth factor in wound healing: synergistic effects with other growth factors. Proc Natl Acad Sci U S A. 1987;84(21):7696-7700.

44. Brownlee M. Biochemistry and molecular cell biology of diabetic complications. Nature. 2001; 414(6865):813-820.

45. Botusan IR, et al. Stabilization of HIF-1alpha is critical to improve wound healing in diabetic mice. Proc Natl Acad Sci U S A. 2008;105(49):19426-19431.

46. Woodley DT, et al. Participation of the lipoprotein receptor LRP1 in hypoxia-Hsp $90 \alpha$ autocrine signaling to promote keratinocyte migration. J Cell Sci. 2009;122(pt 10):1495-1498

47. Bu G, Rennke S. Receptor-associated protein is a folding chaperone for low density lipoprotein receptor-related protein. J Biol Chem. 1996; 271(36):22218-22224.

48. Heldin $\mathrm{CH}$, Westermark B. Role of platelet-derived growth factor in vivo. In: Clark RAF, ed. The Molecular and Cellular Biology of Wound Repair. New York, New York, USA: Plenum Press; 1996:249-273.

49. O'Kane S, Ferguson MW. Transforming growth factor beta s and wound healing. Int J Biochem Cell Biol. 1997;29(1):63-78.

50. Eskild-Jensen A, et al. Endogenous TGF-beta 1 and TGF-beta 2 are not essential for epithelialization and neovascularization in the hairless mouse ear wound model. Ann Chir Gynaecol. 1997;86(3):248-254.

51. Harrington C, Zagari MJ, Corea J, Klitenic J. A cost analysis of diabetic lower-extremity ulcers. Diabetes Care. 2000;23(9):1333-1338.

52. Roberts AB, Sporn MB. Transforming growth fac- 
tor-beta. In: Clark RAF, ed. The Molecular and Cellular Biology of Wound Repair. New York, New York, USA: Plenum Press; 1996:275-308.

53. Brown RL, Ormsby I, Doetschman TC, Greenhalgh DG. Wound healing in the transforming growth factor-beta-deficient mouse. Wound Repair Regen. 1995;3(1):25-36.

54. Hocevar BA, Brown TL, Howe PH. TGF-beta induces fibronectin synthesis through a c-Jun $\mathrm{N}$ terminal kinase-dependent, Smad4-independent pathway. EMBO J. 1999;18(5):1345-1356.

55. Knighton DR, Silver IA, Hunt TK. Regulation of wound-healing angiogenesis-effect of oxygen gradients and inspired oxygen concentration. Surgery. 1981;90(2):262-270.

56. Elson DA, Ryan HE, Snow JW, Johnson R, Arbeit JM. Coordinate up-regulation of hypoxia inducible factor (HIF)-1alpha and HIF-1 target genes during multi-stage epidermal carcinogenesis and wound healing. Cancer Res. 2000;60(21):6189-6195.

57. Tandara Aa, Mustoe TA. Oxygen in wound healing--more than a nutrient. World J Surg. 2004; 28(3):294-300.

58. Semenza GL. Life with oxygen. Science. 2007; 318(5847):62-64.

59. Catrina SB, Okamoto K, Pereira T, Brismar K, Poellinger L. Hyperglycemia regulates hypoxia-inducible factor-1alpha protein stability and function. Diabetes. 2004;53(12):3226-3232.

60. Fadini GP, et al. Diabetes impairs progenitor cell mobilisation after hindlimb ischaemiareperfusion injury in rats. Diabetologia. 2006; 49(12):3075-3084.

61. Gao W, et al. High glucose concentrations alter hypoxia-induced control of vascular smooth muscle cell growth via a HIF-1alpha-dependent pathway.
J Mol Cell Cardiol. 2007;42(3):609-619.

62 . Woodley DT, et al. Intravenously injected human fibroblasts home to skin wounds, deliver type VII collagen, and promote wound healing. Mol Ther. 2007; 15(3):628-635.

63. Qin XF, An DS, Chen IS, Baltimore D. Inhibiting HIV-1 infection in human T cells by lentiviral-mediated delivery of small interfering RNA against CCR5. Proc Natl Acad Sci U S A. 2003;100(1):183-188.

64. Association for the Advancement of Wound Care AAWC. AAWC Multi-disciplinary Statement. AAWC web site. http://aawconline.org/archivedarticles/. Accessed September 8, 2011.

65. Hofman F. Immunohistochemistry. In: Coligan JE, Kruisbeek AM, Margulies DH, Shevach EM, Strober W, eds. Current Protocols in Immunology. Hoboken, New Jersey, USA: John Wiley and Sons, Inc.; 2003: Unit 21.4. 